\title{
Improving educational and labor outcomes through child labor regulation ${ }^{\aleph}$
}

\author{
ELENA DEL REY \\ UNIVERSITAT DE GIRONA \\ SERGI JIMENEZ-MARTIN \\ UNIVERSITAT POMPEU FABRA AND BARCELONA GSE
}

JUDIT VALL CASTELLO

DEPARTMENT OF ECONOMICS \& INSTITUT D'ECONOMIA DE BARCELONA (IEB)

UNIVERSITAT DE BARCELONA \&

CRES, UNIVERSITAT POMPEU FABRA

\begin{abstract}
We explore the effects of a child labor regulation that changed the statutory minimum working age in Spain in 1980. In particular, the reform raised the minimum working age from 14 to 16, while the age for compulsory education remained at 14 until 1990. To study the effects of this change on the incentives to work or study, we consider the different alternatives available at age 14 to individuals born at various times of the year before and after the reform. Before the reform, individuals born at the beginning of the year were legally able to work before finishing compulsory education. We show that individuals born at the beginning of the year were more likely to complete both compulsory and post-compulsory education if they turned 14 after the reform. The increase in educational attainment translates into better labor market outcomes in adulthood only partially. Depending on the level of socioeconomic development of the region, we provide evidence of differential impacts of the reform on men and women and offer plausible explanations for these differences. To the best of our knowledge, this is the first paper that, apart from increases in educational attainment, also finds relevant effects on long-term labor market outcomes from child labor regulations that forbid teenager work. We show that this type of regulation can be a generator of economic development and point to the conditions required for this to be the case.
\end{abstract}

\footnotetext{
"We acknowledge financial help from projects ECO2017-83668-R, ECO2016-76255-P, as well a RECERCAIXA grant. We would like to thank participants at the following seminars and gatherings: Murcia, UPF, URV, IEB (UB), UPO, The Centre for Health Service Economics \& Organization at Oxford University, $39^{\text {th }}$ Congress of the Spanish Economic Association, the Congress of the Spanish Health Economic Association in Granada, and the Barcelona GSE Winter Workshop (2015).
} 


\section{Introduction}

Changes in the legislation regulating minimum school leaving ages allow exploring the consequences of an exogenous change in the level of education and have been used to estimate the causal effect of education on different outcomes. For example, Oreopoulos and Salvanes (2011) review the effect on pecuniary and nonpecuniary returns to schooling; Grenet (2013) focuses on wages (see Dickson and Harmon, 2011 for a review); Anderberg and Zhu (2014) on marital status; Black, Devereux and Salvanes (2008), and Haveman and Wolfe (1984) on fertility; Lochne, (2004) on criminal behavior; Milligan, Moretti and Oreopoulos (2004) and Dee (2004) on voter turnout. For their part, Oreopoulos (2006), Clark and Royer (2013), LlerasMuney (2005), Heckman, Humphries, Veramendi, and Urzúa (2014), and Brunello, Weber, and Weiss (2015) among others, address the impact of education on health behaviors and outcomes.

In contrast, changes in the legislation regulating the minimum age to work have received less attention. On the one hand, Edmonds and Shresta (2012) analyze the effects of minimum age of employment regulation in 59, mostly low income, countries. However, they do not find evidence consistent with enforcement of these rules. Note that child labor can be required in some developing countries to guarantee mere subsistence of the family. When this is the case, enforcement of child labor regulations may be difficult, as children may, and probably will continue to work in the underground economy out of need.

On the other hand, Lleras-Muney and Shertzer (2015) investigate the impact of several policies aimed at assimilating immigrants between 1910 and 1930 in the USA, including laws regulating compulsory schooling and working-age permits. They find that increasing the age required to obtain a work permit resulted in higher educational attainment and earnings, mainly of immigrants. In particular, rising the work permit age by one year increased schooling by about a tenth of a year.

Other work has used the legal age to work as a complement to estimate the returns to education. Acemoglu and Angrist (2000) use the minimum age for a work permit at a given point in time as an instrument for compulsory schooling laws to estimate the returns to education. However, they do not exploit changes in the regulation of the minimum working age over time to identify the specific impact of child labor regulations. Goldin and Katz (2011) and Lleras-Muney (2002) explore the joint effect of state compulsory schooling and child labor laws on high school enrollments in the US from 1910 to 1939. The former find that these policies were only modestly responsible for the substantial increase in secondary school enrolments in the U.S. in that period. The latter, however, finds that the laws increased the education only of those in the lower percentiles of the distribution of education, contributing largely to the decrease in educational inequality. It is worth noting that the minimum age to work was then typically set at a lower age than the age of compulsory schooling. 
In this paper, we focus on a child labor law regulating the minimum statutory working age in Spain in 1980. The reform raised the legal age to work from 14 to 16, without changing the school leaving age. We show that this implied important increases in educational attainment as well as some positive impacts on longterm labor market outcomes for certain groups.

Before the reform, both the school leaving age and the minimum working age were set at 14 years. Under these circumstances, individuals born at the beginning of the year (between January and May) found themselves legally able to work before completing their compulsory education, as they turned 14 before the end of the schooling year in June. This provided an incentive (or at least the legal possibility) for leaving school to work before completing compulsory education. Individuals born at the end of the year reached the legal working age after completing their compulsory education, as they turned 14 after the end of the schooling year in June. In 1980, when the legal age to work increased to 16, this difference in incentives between those born at the beginning and the end of the year was removed. Indeed, to be legally able to work after the reform, individuals needed to be 16, and this occurred more than a year after completing compulsory education. We exploit this difference in incentives affecting individuals born at the beginning and the end of the year (treated and non-treated individuals, respectively) before and after the reform.

We rely on a theoretical model to explain how the observed statistically significant effects could emerge from the change in child labor regulation. To this end, we propose a simple model of educational decisions that shows that some individuals who leave school early due to impatience may continue studying beyond compulsory education if they are forced to attain this basic level of instruction. In other words, some individuals' preferences may be dynamically inconsistent: although they prefer to quit school early, they will attain, when forced to stay, not only the level of education that they obtain by merely staying in school until they can work but also post-compulsory education. Based on a similar model, Cadena and Keys (2015) provide evidence for the existence of such preference reversals in the USA. This approach differs significantly from that explaining child labor in the context of household decisions in developing countries (e.g., Edmonds and Shresta, 2012).

Our results show that the increase in the minimum statutory working age in effect decreased the number of early school leavers (individuals not finishing compulsory education, henceforth ESL). In particular, we find that the reform reduced the number of ESLs by $7.6 \%$ in the case of men and by $11 \%$ in the case of women. We refer to dropouts (henceforth DO) as individuals who do not attain any level of post-compulsory education. By definition, a reduction in the number of early school leavers who later do not attain postcompulsory education leaves the number of dropouts in the cohort unchanged. If the number of DO also falls, the number of individuals attaining post-compulsory education must be increasing. We find such positive impact on post-compulsory education attainment. Specifically, we observe that dropouts fell on 
average by $3.3 \%$ for men and by $2.7 \%$ for women. We also report significant increases in university education for men.

In addition, we show that this child labor regulation had some significant labor market effects in the longterm. Using the Spanish Labor Force survey, we show that working accidents fell for both men and women as a result of the increase in educational attainment. We also prove that, for treated men, the reform increased wages and the overall probability of working, and it decreased the probability of working in a lowskilled sector. However, we do not find any significant effect for women. The apparent absence of long-term labor market effects for women, in spite of the important increases in educational attainment mentioned before, motivates a division of the sample by regions according to their level of socioeconomic development that allows further insight to the effect of the policy on both genders. In particular, we first find that, in fact, for men, the positive impact of the reform concentrates in less developed regions, where the incentives to attain a higher level of education seem to have been stronger in terms of wages. We provide evidence that wages may have been in some cases higher for non-educated men in more developed regions and this may have induced boys out of secondary education in spite of the reform. Second, we are able to see that the positive effects of the reform on the educational attainment of women concentrate conversely in more developed regions. Since these were the regions where secondary educational attainment of women was higher to begin with, we believe that social norms may have played a role in this outcome. Still, even in these regions, the positive effect on educational outcomes for women does not translate into improved labor market outcomes, perhaps due to the existence of stereotypes against women working outside the home, still strong at the time in Spain. Indeed, as we will see, activity rates of women in Spain were among the very lowest in the European context during the 80s.

Summing up, the division of the sample by regions according to the level of socioeconomic development allows a deeper understanding of the mechanisms in place. In particular, we are able to see that the change in the incentives to complete education induced by the reform may have been dominated by other, potentially stronger, limitations or incentives that did not change with the reform. Absent these limitations, our results underline the role of impatience in educational decisions made by the young and provide relevant information for policy-makers. To the best of our knowledge, this is the first paper that, apart from increases in educational attainment in the short run, also finds important positive impacts on long-term education and labor market outcomes from child labor regulations that induce teenagers to stay longer at school. Hence, this type of regulation can represent an important road to foster economic development in developing countries where child labor is no longer strictly necessary for family subsistence. Moreover, the heterogeneous effects found across regions for men and women also point to the role of the existing socioeconomic environment in hindering or enhancing the positive results of child labor regulations on education and labor market outcomes. 
Another paper that exploits the same reform (Bellés et al. 2015), provides additional evidence of the impact of the increase in the minimum working age on both fertility decisions and infant health outcomes. The results show that this same child labor regulation decreased marriage and fertility rates and deteriorated infant health outcomes mainly due to the postponement in the age of delivery. However, Bellés et al. (2017) also show that more educated parents were able to reverse, in the long-run, these negative shocks on their children at birth. This reversal operates mainly through increased parental vigilance.

The rest of the paper is organized as follows. Section 2 describes the reform. Section 3 presents a theoretical model that explains how impatience can affect, before the change in the law, the educational decisions of individuals born at different times of the year. Section 4 presents the data, empirical strategy and main results for educational attainment. Section 5 presents the long-term labor market impact of the child labor regulation. In Section 6 we explore the existence of heterogeneous effects across regions in Spain according to the social development of each region, Section 7 provides additional robustness checks, and Section 8 concludes.

\section{The 1980 reform; increase in the minimum working age from 14 to 16}

Spain's 1970 General Education Law established eight years of compulsory education, starting in the calendar year children turned six. At the time, the legal working age was 14. Note that individuals can drop out of school as soon as they reach the legal working age. Therefore, during the 70s, individuals turning 14 at the beginning of the year could leave school and start working before completing the eight years of compulsory education (in June), thus becoming ESL (see Figure A1 in the appendix). Note that in the Spanish educational system, all children from the same calendar year start school the same year (children born in the same birth cohort belong to the same school cohort). Consequently, children born at the beginning of the year start school at an older age (in months) than those born at the end of the year.

A significant fraction of children was indeed participating in the labor market in Spain before the second quarter of 1980. The top panels of Figure 1 present labor force participation (LFP) and employment rates of 14 and 15-year-olds in the five years preceding the reform, according to the Spanish labor force data. We can see that, for example, in the fourth quarter of 1978, labor force participation rates of 14-year-olds were 14 percent ( 8 employed) for boys and 10 percent ( 5 employed) for girls. For 15 -year-olds the same rates were 36 percent ( 24 employed) for boys and 25 percent ( 15 employed) for girls. 
In March 1980, a new law regulating labor relations (Estatuto de los Trabajadores) was passed by the Spanish parliament. It prohibited child labor under the age of $16 .{ }^{1}$ This was a sea change for children born at the beginning of the year as they no longer had an incentive to stop attending school before completing compulsory education. As a result, the effect of this law was to logically raise educational attainment, since children born both at the beginning and at the end of the year could no longer work as an alternative to attending school until the age of 16 (see Figure A2 in the Appendix).

In principle, there is no reason to expect an effect of the reform on post-compulsory education attainment. One could assume that the incentives present for children born at the beginning of the year would also apply at the age of 16. Then, those individuals who could not join the labor market at the age of 14 after the change in the law, would do so at the age of 16 before attaining the first level of post-compulsory education, thereby being classified as dropouts (henceforth referred to as DO). The fall in the numbers of ESL due to the reform would be offset by an increase in the number of children who would not finish their postcompulsory education (Bachillerato at that time): the number of DO would be constant.

Alternatively, it could also be the case that, by increasing the number of children attaining compulsory education, the law made it possible for some of them to complete post-compulsory education. But why would those individuals who wanted to quit school at age 14 and were forced to stay, actually go on and finish post-compulsory education? A possible explanation for this temporal inconsistency is that some children are impatient at the age of 14 and fail to realize that, if they finish compulsory education, their best choice will be to complete some form of post-compulsory education subsequently. Accordingly, if that is the case, we could argue that, by forcing students to complete compulsory education, the change in the law regulating labor relations in 1980 would also increase post-compulsory attainment. The model we propose in Section 3 elaborates on these ideas and makes some predictions about the reform's potential effects on postcompulsory educational attainment.

As shown in Figure A3 in the appendix, the minimum leaving age for compulsory education did not change until 1990 (rising from 14 to 16). Thus, we can be confident that there were no other reforms that could undermine our identification strategy.

In addition, we have found evidence that the reform was implemented quite effectively from a legal point of view. Administrative data confirm the radical elimination of formal work for children that turned 14 after the introduction of the reform. The left bottom panel of Figure 1 shows the distribution in the age of the first Social Security contribution for the pre-reform (turned 14 before the reform: therefore, born between 1961

\footnotetext{
${ }^{1}$ The only exception stated in the law concerned the participation of minors in specific public shows, that remained subject to authorization by the competent authorities provided that this did not endanger their physical health or their professional and human training (Art. 6).
} 
and 1965) and post-reform cohorts (turned 14 after the implementation of the reform: hence, born between 1967-1971). We can see that pre-reform cohorts have a probability of contributing to the Social Security system before age 16 of 9.22 percent for boys and 7.57 percent for girls. For the post-reform cohorts, these numbers drop to 0.17 percent for the case of boys and 0.17 percent for girls. Thus, the available evidence confirms that the reform was fully effective in reducing formal child labor for the cohorts that turned 14 after the reform.

Much more difficult to document is the labor market impact of the reform on the cohorts that were 14 and 15 at the time the reform was introduced, which could already be (legally) working before the reform (cohorts of 1965 and 1966). The law does not specify any special treatment for those cohorts. If we look at social security contributions for those specific cohorts (1965 and 1966) we document that formal work was completely eliminated for those cohorts if they had not started contributing before the reform. If they were already working before the reform, we see that some of them continue contributing also after the reform. On the other hand, getting additional information on the labor market status of these cohorts from survey data is more complicated as the Spanish Labor Force Survey stopped reporting labor force status of children below 16 from the second quarter of 1980, that is, in the first quarter after the reform as it was suddenly illegal to work at these ages. Yet, the Spanish Budget Survey of 1980-81 (EPF80-81, see Alonso-Colmenares et al., 1999 for a description) reveals that only 2.1 percent of the 14-year-old boys and 1.2 percent of the 14-yearold girls were participating in the labor market in the year following March 1980 (the EPF80-81 run from April 1980 to March 1981). The same survey shows that 9.63 percent of the 15 -year-old boys and 5.1 percent of the 15-year-old girls participated in the labor market. These numbers are much lower than those reported in Figure 1 for the same ages for the pre-reform cohorts. Thus, we conclude that formal and informal work almost disappeared for the 14-year-old cohort but not entirely so for the 15-year-old cohort (although it was greatly reduced). Thus, in our baseline specification we will consider the 15-year-old cohort as the first control cohort and, later on, we will exclude that (potentially partly treated cohort) to assess the robustness of our results.

\section{A model of educational decisions}

We consider a simple model of educational decisions where an individual, characterized by her level of impatience (or present bias), decides whether to continue studying or work. We distinguish between treated (or affected by the reform) and non-treated, or control individuals (not affected by the reform). Concerning the decision to complete compulsory education or not, only individuals born at the beginning of the year are affected by the reform that rose the legal working age to 16. Indeed, before the reform (when the legal working age was 14), individuals born at the beginning of the year faced on their 14th birthday the choice between quitting school to work without a diploma or waiting to complete the academic year and join the 
job market with the compulsory education diploma. When children born after June attained the legal working age, they had already completed mandatory education.

Therefore, treated individuals faced two subsequent decisions before the law change came into effect. First, on their 14th birthday, as they attained the legal working age, they had to decide whether to complete compulsory education or not. We call early school leavers (ESL) those who did not complete compulsory education. Second, on their 16th birthday, they had to decide whether to attain some post-compulsory education level or join the labor market. Those who entered the labor market at this stage, together with ESL, integrate the number of DO, i.e., individuals who do not attain any post-compulsory education. Individuals not affected by the reform (non-treated individuals) only decided at age 16 and could, therefore, be DO or attain post-compulsory education, but they could no longer be ESL.

To analyze these decisions, we consider a simple three-period model of educational choices where individuals decide whether to continue studying or work.

Each individual is characterized by a level of impatience that reduces the weight given to the future at each point in time, interacting with conventional exponential discounting that gives lower weights to those events that are further away from the present (O'Donoghue and Rabin, 1999). Although this approach may not be necessary to obtain the results predicted by the model, impatience provides a very simple and intuitive framework to analyze this issue as will be made clear.

In the first period, before the reform, when treated individuals turn 14, they have to decide whether to leave school and join the labor market and earn $y_{0}$ or continue studying and on family support and consume $s$. There are no savings. Hence consumption in the first period, $c_{0}$, is either $s$ or $y_{0}$.

In the second period, ESLs continue to earn a low wage (perhaps increased by work experience, although for simplicity, we omit this from the model); those who attained compulsory education have to decide whether to join the labor market and earn $y_{l}$ or continue studying to attain some post-compulsory education. In the latter case, they remain on family support consuming $s$. Finally, in the third period, ESLs earn $y_{0}$, individuals with only compulsory education earn $y_{1}$, and individuals with post-compulsory education are paid $y_{2}$. No decision is made at this third stage.

Individual lifetime utility, considered by the individual in the first period, can therefore be written

$$
U=U\left(c_{0}\right)+\gamma\left[\delta U\left(c_{1}\right)+\delta^{2} U\left(c_{2}\right)\right]
$$

with $\gamma \epsilon[0,1]$, and distributed according to $F(\gamma)$ with $F^{\prime}(\gamma)=f(\gamma)$. Notice how $\gamma<1$ reduces the weight given to future utility. 
To find the sub-game perfect Nash equilibrium, we analyze individual decision-making by backward induction. In the second period, all individuals know whether they have attained compulsory education or not. Treated individuals who did not complete compulsory education (ESL) do not make any decision at this stage. Non-treated individuals and treated individuals who completed compulsory education at the first stage now decide whether to continue studying and get $U(s)+\gamma \delta U\left(y_{2}\right)$ or quit and join the labor market and get $U\left(y_{1}\right)+\gamma \delta U\left(y_{1}\right)$. Note that period 2 is at this stage "the present": the utility already obtained in the first period does not affect decisions, and the parameter $\gamma<1$ operates only on the utility of the third period (period 2).

Individuals who attained compulsory education in the first period will continue studying in the second period provided that

$$
U(s)+\gamma \delta U\left(y_{2}\right)>U\left(y_{1}\right)+\gamma \delta U\left(y_{1}\right)
$$

Condition (2) allows us to derive a threshold of above which individuals decide in the second period to attain post-compulsory education, and below which they attain only compulsory education:

$$
\hat{\gamma}=\frac{U\left(y_{1}\right)-U(s)}{\delta\left(U\left(y_{2}\right)-U\left(y_{1}\right)\right)}
$$

Individuals with $\gamma<\hat{\gamma}$ attain only compulsory education. We call these individuals less patient individuals. Clearly, if $\hat{\gamma}>1$ all individuals are in this case. Individuals with $\gamma>\hat{\gamma}$ are more patient: they will attain post-compulsory education in the second period. If $\hat{\gamma}<0$, all individuals attain post-compulsory education.

We now move to the analysis of period 1 where, before the reform, treated individuals chose whether to complete compulsory education or not. They anticipate their behavior in period 1 based on their level of impatience .

- Less patient individuals in period $2(\gamma<\hat{\gamma})$ anticipate that, if they reach the compulsory education level, they will not attain post-compulsory education since, for them, $U(s)+\gamma\left[\delta U\left(y_{2}\right)\right]<U\left(y_{1}\right)+$ $\gamma\left[\delta U\left(y_{1}\right)\right]$. They will complete compulsory education in the first period only if their lifetime utility with compulsory education exceeds lifetime utility with no education

$$
U(s)+\gamma\left[\delta U\left(y_{1}\right)+\delta^{2} U\left(y_{1}\right)\right]>U\left(y_{0}\right)+\gamma\left[\delta U\left(y_{0}\right)+\delta^{2} U\left(y_{0}\right)\right]
$$

or

$$
\gamma>\frac{U\left(y_{0}\right)-U(s)}{\left(\delta+\delta^{2}\right)\left(U\left(y_{1}\right)-U\left(y_{0}\right)\right)}=\underline{\gamma}
$$


Hence, among the less patient, with $\gamma<\hat{\gamma}$, there may be a group of very impatient individuals, with $\gamma<\underline{\gamma}<\hat{\gamma}$, that will not complete compulsory education. These will be ESL. All that is required for this group to exist when $s<y_{0}<y_{1}$ is that $\underline{\gamma}>0$. In contrast, note that (4) is never true if earnings without education surpass earnings with basic education and family support. Then no one in this group completes compulsory education independently of impatience (see Section 6).

- $\quad$ More patient individuals in period $2(\gamma>\hat{\gamma})$ anticipate that, if they reach the compulsory education level, they will attain also post-compulsory education, because, for them, $U(s)+\gamma\left[\delta U\left(y_{2}\right)\right]>U\left(y_{1}\right)+$ $\gamma\left[\delta U\left(y_{1}\right)\right]$. Still, and importantly, they will only complete compulsory education in the first period provided that their lifetime utility with compulsory education exceeds lifetime utility without compulsory education:

$$
U(s)+\gamma\left[\delta U(s)+\delta^{2} U\left(y_{2}\right)\right]>U\left(y_{0}\right)+\gamma\left[\delta U\left(y_{0}\right)+\delta^{2} U\left(y_{0}\right)\right]
$$

or

$$
\gamma>\frac{U\left(y_{0}\right)-U(s)}{\delta\left(U(s)-U\left(y_{0}\right)\right)+\delta^{2}\left(U\left(y_{2}\right)-U\left(y_{0}\right)\right)}=\bar{\gamma}
$$

Thus, most patient individuals, with $\gamma>\bar{\gamma}$, attain compulsory education and, later, post-compulsory education. However, if $\hat{\gamma}<\bar{\gamma}$, there is a group of individuals with $\gamma$ such that $\hat{\gamma}<\gamma<\bar{\gamma}$, who, although patient enough to complete post-compulsory education in the second period given the payoffs at stake then, they are not patient enough at stage 1 to complete compulsory education. Not letting these individuals decide whether to complete compulsory education at stage 1 (as the labor market reform did in Spain in 1980) will raise the levels of post-compulsory education attainment.

We summarize our findings in Figure 2 that refers to individuals with identical $y_{0}, y_{1}, y_{2}, s$ and $\delta$, that differ only in $\gamma$.

Data available on Spanish wages in the 1980s show that the average annual wage income for men with no education, $y_{0}$, was 56,288 pesetas (338.3 Euro). With a basic diploma, $y_{1}$, it was 57,122 pesetas (343.31 Euro) and with some post-compulsory education, $y_{2}$, it was 62,020 pesetas (372.75 Euro). Assuming logarithmic utility, individuals with $=.95$ and an income equivalent of living on family support, $s$, of 54,000 pesetas (324.55 Euro) attain both compulsory and post-compulsory education when we do not account for impatience $(=1)$. For individuals who share these values of the parameters and differ only in degree of impatience $\gamma$, we have $\underline{\gamma}>1, \hat{\wedge}=.72$, and ${ }^{-}=.86$. Therefore, if allowed to leave school early, all those with $\gamma<\bar{\gamma}=.86$ will quit and all those with $\gamma>.86$ will attain both compulsory and postcompulsory education. When forced to complete compulsory education, all those with $\gamma<\hat{\gamma}=.72$ will attain only compulsory education, while all those with $\gamma>.72$ will also attain post-compulsory education. 
Therefore, individuals with $\gamma \epsilon(.72, .86)$ will leave school early if allowed to, but will complete postcompulsory education if they are forced to complete the mandatory level.

More generally, for some individuals who would attain post-compulsory education if they had the compulsory level to actually be early school leavers before the reform we need that, for them, $\bar{\gamma}>\hat{\gamma}$ (see Figure 2). A first necessary condition for this to be the case is that $s<y_{0}<y_{1}<y_{2}$ : family support must be less than earnings with any level of education, and earnings must increase with education. ${ }^{2}$ Manipulating the condition $\bar{\gamma}>\hat{\gamma}$ using Equations (3) and (7), we can see that, in addition, we also need that

$$
U\left(y_{2}\right)-U(s)>\delta\left(U\left(y_{2}\right)-U\left(y_{0}\right)\right) \frac{U\left(y_{1}\right)-U(s)}{U\left(y_{0}\right)-U(s)}
$$

The necessary condition $s<y_{0}<y_{1}<y_{2}$, and the fact that $\delta<1$ imply that $U\left(y_{2}\right)-U(s)>\delta\left(U\left(y_{2}\right)-\right.$ $\left.U\left(y_{0}\right)\right)$. Then, a reasonable sufficient condition for (8) to be true is that earnings with basic education $y_{1}$ and earnings with no education $y_{0}$ be not too dissimilar, so that the fraction term in the right-hand side of (8) is not too large.

\section{The effect of the child labor regulation on educational attainment}

In this section we test the following predictions: first, the reform removed the incentive for individuals born in the first months of the year to leave school before completing compulsory education when turning 14 , i.e. the number of early school leavers (ESL) decreased among individuals born in the first half of the year. Second, the reform induced some of those individuals (born in the first months of the year) to also complete some post-compulsory education, i.e. the number of DO also decreased.

To do that, we use the Spanish Labor Force Survey (LFS) for the 2000-2013 waves. ${ }^{3}$ Although the LFS is available from 1976 onwards, information on the month of birth, which is a crucial variable for our identification strategy, is only available as of $2000 .{ }^{4}$ We omit from the sample all immigrants (individuals not born in Spain), as we cannot guarantee that they studied in Spain, and were thus affected by the reform. ${ }^{5}$

We compare two educational outcomes for individuals born in the first/last months of the years before and after the introduction of the reform. In the pre-reform cohorts, we include individuals who turned 14 before

\footnotetext{
${ }^{2}$ If $y_{2}>y_{1}>s>y_{0}, \bar{\gamma}<0$ and $\hat{\gamma}>0$ so it cannot be the case that $\bar{\gamma}>\hat{\gamma}$ (there are some ESL but all those who attain compulsory, attain post-compulsory). Similarly, if $y_{2}>s>y_{1}>y_{0}$ or $s>y_{2}>y_{1}>y_{0}$ both $\bar{\gamma}$ and $\hat{\gamma}$ are negative: everyone attains postcompulsory education. Detailed calculations are available upon request.

3 "Encuesta de Población Activa" in Spanish. More information on the Spanish Labor Force Survey can be found in the data section of the appendix.

${ }^{4}$ Individuals may remain in the LFS for up to six periods but we restrict the sample to one observation per individual since we are looking at basic educational attainment and this is unlikely to change during adulthood.

${ }^{5}$ The boom in immigration in Spain occurred during the first half of the 2000s, so those individuals were not affected by the reform introduced in 1980 .
} 
the implementation of the reform (cohorts born between 1957 and 1965). The post-reform group includes individuals who turned 14 after the introduction of the reform (cohorts born between 1967 and 1976). We omit the cohort born in 1966 because they turned 14 in 1980, the year the reform was introduced. We drop this cohort for two main reasons; first, the law was passed in March (towards the end of the educational year which finishes in June) so that it is not clear the degree of enforcement of the law during this first year. Second, there are a proportion of students who may be retained and, as our identification strategy is based on birth cohort we want to minimize this potential problem of misclassification of individuals.

One potential concern with our specification is that individuals born in January and December are typically quite different in several dimensions, as reported in several studies (see, for example, Bound and Jaeger: 2000 or Buckle and Hungerman; 2013). Those papers typically find that individuals born in the first quarter of the year (January, February and March) have better educational and employment outcomes than individuals born in the other three quarters of the year. For example, Buckle and Hungerman (2013) show that individuals born in the first quarter of the year earn wages that are $1 \%$ higher than individuals born in the other quarters. As we are estimating the effects by looking at the difference between treated and control individuals before and after the policy change, these differences between individuals born at the beginning and end of the year should cancel out when making the before-after comparison if they are constant over time. If that is the case, those constant differences between beginning and end of the year should not affect our results. However, it could be the case that the differences could evolve over time and could, somehow, change at the same time that the reform is introduced, which would bias our results. We believe that this is, most probably, not the case as the literature on the topic reports that these differences in outcomes according to the quarter of birth are present for several cohorts and are, thus, quite time invariant. In any case, in order to address the possible doubts remaining over comparing two potentially different groups of individuals over time, we omit from our sample those individuals born in the first and last two months of each year. Thus we effectively compare the outcomes of individuals born in months 3, 4 and 5 with those born in months 8, 9 and 10 before and after the reform. If we come back to the literature about the differences in season of birth, we can see that individuals born in the second and third quarter of the year are significantly more similar than individuals born in the first or four quarters.

We define a person as an ESL if he/she is illiterate or has not completed compulsory education ${ }^{6}$. A dropout is an individual who has not completed upper secondary education (i.e., a person that, at most, has completed the first stage of secondary education). ${ }^{7}$

\footnotetext{
${ }^{6}$ It has to be noted that the LFS that we use was collected between 2000 and 2013. In the year 2000 the age for compulsory schooling was 16 (it was increased from 14 to 16 in 1990) and primary education was only until age 12. Thus, the first stage of secondary education became also compulsory (from age 12 to 16). Therefore, we have created the definition of ESL using the
} 
For each of these two outcomes, we apply the following model:

$$
\text { Outcome }_{i c t}=\alpha+\beta_{1} \text { Treat }_{i c}+\beta_{2} \text { Treat }_{i c} * \text { Post }_{c}+\beta_{3} \text { URentry }_{c j}+\delta_{t}+\delta_{t} * \text { Treat }_{i c}+\theta_{j}+\mu_{c}+\varepsilon_{i c t}
$$

where Outcome $_{\text {ict }}$ is either ESL or dropout for individual $\mathrm{i}$ that belongs to cohort $\mathrm{c}$ and is observed in period t. As explained above, we define individuals as treated if they were born in months 3, 4 and 5 of each cohort, and in the control group if they were born in months 8, 9 and 10. Post is one for the cohorts born after 1966. We also include a control for the regional unemployment rate at the time of turning 14 $\left(U R e n t r y_{c j}\right)$. We include time fixed effects $\left(\delta_{t}\right)$, region fixed effects $\left(\theta_{j}, 17\right.$ Autonomous Communities) as well as cohort fixed effect $\left(\mu_{c}\right)$. We also interact these time fixed effects with the treatment variable to allow for differential time effects in the treatment and control groups. The model is estimated separately for men and women as the educational evolution of the affected cohorts show strong gender differences.

In this context, $\beta_{2}$ identifies the impact of the policy change after controlling for seasonal, regional as well as cohort effects. ${ }^{8}$ Finally, we cluster the standard errors at cohort level in all our specifications. ${ }^{9}$ As the number of cohorts included is 19 , we also present the Wild-Boostrap p-values in all our specifications to account for the small number of clusters. Therefore, the standard errors clustering by cohort are presented in parenthesis while the Wild-Bootstrap p-values are presented in brackets in the tables of results. Finally, we apply the reweighting scheme suggested by Hainmueller (2012) that improves covariate balance and maximizes similarities between the treatment and control groups which, in turn, help making the parallel trend assumption more plausible. We use the unemployment rate of the region, year of birth and region as covariates to apply the balance procedure.

Figure 3 plots the probability of being an ESL and a dropout for each cohort born between 1957 and 1976. The figure differentiates between individuals born at the beginning of the year (months 3,4 and 5) and individuals born in the last months of the year (months 8,9 and 10), and shows the raw data in dots and the predictions from the model with linear and quadratic trends. The left panel in Figure 3 shows that, before the

\footnotetext{
school system of the year 2000 (when the survey was collected) and we have tried to adjust the definition of the new system to the one corresponding to the old educational system. In any case, this change only affects the definition of ESL, and the results using a more restricted version of the ESL definition (using only as ESL those that report not having completed primary education in the survey years 2000-2013, available upon request) point to the same direction than our baseline results.

${ }^{7}$ For both outcomes, we also apply the condition of not being a student at the time of the survey in 2000-2013. However, if we do not include this restriction in the definition results are almost the same, as there are few individuals still studying at these ages.

${ }^{8}$ We have estimated an alternative specification of this model with pre- and post-reform trends instead of cohort dummies and the results obtained are the same. The results obtained from these tests are available from the authors upon request.

${ }^{9}$ For the employment outcomes (Section 5) and for the heterogeneity exercise in which we estimate separate regressions for more/less developed regions (Section 6), we use the same model and we also perform the Romano and Wolf multiple hypothesis testing (Romano and Wolf 2005a, 2005b, 2016). The reason is that, in these cases we estimate more than four outcomes so that it is necessary to check significance levels for false positives due to multiple hypotheses. All of the significant coefficients remain significant after applying the Romano and Wolf corrections; results are available upon request.
} 
reform, individuals born during the first months of the year had a higher probability of being an ESL as compared to individuals born in the last months of the year. This gap closes once the reform is introduced in 1980 and the minimum working age increases to 16 . Therefore, individuals born at the beginning and end of the year after the reform have the same probability of being ESLs. This is an expected result, as the option of working is no longer available at age 14, and this eliminates all the incentives to quit studying before completing compulsory education in order to find a job. The differences shown in the Figure can also be observed in Table A3 in the appendix, which reports the mean for ESL and dropouts for cohorts born before or after 1966 for the treated and the control group. Again, these numbers represent raw averages across these different groups and we can observe that the reduction in ESL and dropouts for cohorts born after 1966 is stronger for the treated than for the control group.

We now turn to the results of the econometric model outlined above, as shown in Table 1, we estimate that the fall in the probability of being an ESL due to the policy's implementation corresponds to 1.24 percentage points for men and 1.41 percentage points for women.

The results in Table 1 also show that the probability of being a dropout decreased by 1.63 percentage points for men, and by 1.23 percentage point for women. The results are significant for both men and women.

In order to obtain a clearer idea of the size of these effects, we perform a back-of-the-envelope calculation of the absolute number of individuals affected by the reform by taking into account the number of treated men/women in the affected cohorts. At the mean of the dependent variable, we find that the reform reduced the number of ESLs by $7.6 \%$ in the case of men and by $11 \%$ in the case of women (the mean in ESL for the cohort of 1965 is $16.19 \%$ for men and $12.71 \%$ for women). By definition, a decrease in ESLs who attain only the compulsory education level leaves the number of dropouts unchanged. In contrast, we observe that average dropouts fell by $3.3 \%$ for men and by $2.7 \%$ for women. Although this effect seems smaller than that on ESL, note that the mean in dropouts for the cohort of 1965 is $49.3 \%$ for men and $43.8 \%$ for women. ${ }^{10}$ Thus, our back-of-the-envelope calculation suggests that in the first ten post-reform cohorts, the number of ESL fell by 16,810 men and 20,130 women, whereas the number of dropouts fell in 22,230 men and 17,030 women as a result of the introduction of the child labor regulation. Thus, as predicted by the theoretical model, forcing students to complete compulsory education also induced some students to complete some post-compulsory education.

By the same logic provided by the theoretical model in section 2, we could also argue that the reform would not only provide incentives for individuals to finish both compulsory and post-compulsory education but also to access higher education. We therefore perform the same estimation for the probability of having studied at the university level (having completed at least three courses of any university degree). Table 2

\footnotetext{
${ }^{10}$ The number of ESLs in the last pre-reform cohort, 1965, was of 22129 treated men and 18306 treated women. The number of dropouts in 1965 was 67386 among treated men and 63084 among treated women.
} 
reports the results of this regression, and we can see that the reform's effects on the probability of studying at the university level are significant only for men. The coefficients for women go in the same direction, pointing towards an increase in the probability of studying at the university level as a result of the reform, but the effects are not significant.

Finally, we use an alternative data source to strengthen our findings on the effect of the reform on educational outcomes. Table A1 in the appendix reports the results for the same dependent variables using an alternative database: a five percent representative sample of the 2001 census data (from Spain's National Institute of Statistics - INE). ${ }^{11}$ The results obtained from this analysis have to be considered with caution, as we cannot construct the exact same definitions of ESL and dropout with the census data than one we have with the LFS. However, even with this limitation in mind, the results point to the reform's major impact on reducing the probability of being an ESL and dropout for treated individuals. Thus, these results confirm the reform's impact on the probability of completing compulsory and post-compulsory education for treated individuals.

\section{The effect of the child labor regulation on long-term labor market outcomes}

In this section, we investigate the potential effects of the child labor regulation on the labor market outcomes of affected workers in the long term. We focus on the probability of working, on the type of jobs of affected workers, on wages as well as on the probability of suffering from a working accident. In principle, it seems reasonable to expect that an increase in the minimum working age that raised the level of education will have a positive long-term impact on both the quantity and the type of employment as well as on the likelihood of suffering a working accident.

We first use the LFS for the 2000-2013 waves (as before), and use the same model (equation 9) than for the educational outcomes. The outcomes analyzed with the LFS are the probability of working, the probability of working in the construction sector (a sector representing more than 10\% of GDP in the Spanish economy in 2002-2011 and employing mainly low skilled men), the probability of having a low-skilled job, and the probability of being inactive (which may be important for the case of women). As the LFS does not include information on wages, we use EU-SILC data from 2004 to 2015 in order to obtain information on wages. As before, standard errors are clustered at the cohort level and Wild Bootstrap p-values are reported in brackets. Table 3 reports the labor market results for men and women in our sample. In the case of treated men (panel A), we find that the reform significantly increased the probability of working and it decreased both the probability of being a low-skilled worker as well as the probability of working in the construction sector in

\footnotetext{
11 The Spanish Census does not include information on the number of years of education and it only provides information on the highest educational degree obtained, as in the Labour Force Survey.
} 
2000-2013. ${ }^{12}$ Furthermore, these improvements in labor market conditions were also translated into significant increases in wages by $5 \%$. Thus, the reform not only increases men's employment but it also changes the skill level of jobs as well as wages for treated men.

The picture looks different in the case of women (panel B). We can see that, although most of the coefficients of the impact of the reform have a similar sign as those of men, none of them is statistically significant.

The reported absence of long-term labor market effects for women, even if we have reported important increases in educational attainment for both men and women, motivates the division of the sample by level of regional development in Section 6. Before moving there, and to conclude this section, we explore an additional outcome that is related to the quality of the job and that may also be affected by an increase in the level of education of the workers: workplace accidents. By delaying the entrance into the labor market and increasing the educational attainment of affected workers, the child labor regulation introduced in 1980 could have led to an improvement of the working conditions and, thus, to a reduction in the likelihood of suffering a working accident. To empirically corroborate this hypothesis, we use register data for all workplace accidents recorded in Spain from 1988 through to 2013. In order to include individuals of the same ages, we restrict the sample to the cohorts of 1960-1972 and ages 28-41. We collapse the individual data by region and cohort for the treatment and control groups, and divide it by the population for each cohort of treated and control individuals. We estimate the same model than for the educational outcomes but using collapsed data. In Table 4 we can see that the reform reduced the probability of suffering a workplace injury for both men and women. The size of the effect is twice as large for men as for women, which is consistent with the long-term differential impact of the reform on labor market outcomes between men and women. As men get access to more skilled jobs, the reduction of working accidents comes from both higher education levels as well as less dangerous jobs, whereas the reduction in working accidents for women only comes from the increase in the level of education of affected women. Finally, the reform does not have a significant impact when we restrict the sample to include only those workplace accidents that lead to the worker's death.

\section{Heterogeneity of results by level of development of the region}

The results presented so far display the average effects of the child labor reform in 1980 in the entire Spanish territory, and may hide heterogeneous results across regions. Indeed, the differences in development across regions in Spain have traditionally been notorious. For example, in 1981 while the average national illiteracy rate was 7,92 \%, it was only $1,57 \%$ in Cantabria, but as large as $15 \%$ in Andalucia. Differences in

\footnotetext{
${ }^{12}$ Since we include cohorts from 1956 to 1976 and survey years 2000-2013, we are measuring employment effects for ages 24-57.
} 
illiteracy rates across gender were also remarkable: while, in Cantabria, the illiteracy rate for women was $56 \%$ higher than for men, in Valencia it was $211 \%$ higher (Tena, 1981). ${ }^{13}$

In view of these facts, we believe that the variables that drive the results according to the model in Section 3 are likely to differ across regions as well as gender. In particular, the change in the incentives to complete education induced by the reform may be dominated by other, potentially stronger, incentives that did not change with the reform. For this reason, we now divide the 17 Autonomous Communities in Spain into two groups according to the "social development of the region" in 1980. We denote as "more socially developed regions" those regions that score high both in the total activity rate and secondary education attainment for women: Madrid, Basque Country, Cantabria, Canary Islands, Catalonia, Balearic Islands, La Rioja, Asturias and Navarre. The remaining 8 regions (Andalucía, Aragón, Castille-León, Castille-La Mancha, Extremadura, Galicia, Murcia, Valencia) are classified as "less socially developed regions".

\subsection{Effects of the reform on education by region}

In Table 5 we can see that, neither the probability of being an early school leaver nor the probability of being a dropout is significantly affected for treated men in more developed regions. In contrast, in less developed regions, the probability of men being ESL decreased by 1.83 percentage points, and the probability of being a DO decreased by 2.8 percentage points. Thus the effect of the reform on educational outcomes for men is geographically concentrated and larger than previously reported.

A tentative explanation for this finding is that the wage gain from having compulsory education was very low for men in developed regions; to see this we compared average wages in 1980-1982 by educational level and gender for both groups of regions using retrospective data from the Spanish Continuous working histories in the 2004-2016 period. Although the quality of these data is low, there is some evidence that wages of less educated young men in more developed regions may have been higher than wages of more educated young men in the same regions (although the difference is not statistically significant). ${ }^{14}$ Therefore, these wage differences provide an incentive to leave school early that was not removed by the reform. This explanation is consistent with the model derived in Section 3. Furthermore, men in less developed regions were working in greater numbers and were less educated in the year previous to the reform (LFS, 3rd quarter of 1976); thus, the margin of educational improvements for young men as a result of the child labor reform was higher in these less developed regions.

For women, the contrary applies; the impact of the reform on educational attainment has stronger consequences for treated women in more developed regions. Although the probability of being an early

\footnotetext{
${ }^{13}$ The literature has reported significant differences in both literacy rates between men and women as well as discrimination rates against women across Spanish regions as early as the 1870's (Beltrán and Gallego, 2015).

${ }^{14}$ (http://www.seg-social.es/Internet_1/Estadistica/Est/Muestra_Continua_de_Vidas_Laborales/index.htm).
} 
school leaver is reduced after the reform for women in both more and less developed regions, the reduction in the probability of being a dropout is only significantly reduced for women in more socially developed regions. It is worth noting that more socially developed regions are precisely those where women secondary education attainment levels were already higher before the reform. For this reason, we believe that stereotypes and social norms play a fundamental role and are likely driving the results for the case of women.

\subsection{Effects of the reform on labor outcomes by region}

The heterogeneous effects in educational attainment across regions and gender translate into differential impacts in long-term labor market outcomes. Table 6 reports the results on labor market outcomes and wages for men. As expected, we can see that the reform only has a significant impact on treated men in less developed regions (panel B). More specifically, we find that the child labor regulation reform significantly increased the probability of working, decreased the probability of working in the construction sector and decreased the probability of working in a low-skill sector for treated men in less developed regions. Furthermore, wages also increased for treated men after the reform in less developed regions. On the other hand, none of the employment outcomes is significantly affected by the reform for treated men in more developed regions (panel A). Thus, we can say that, in the case of men, all the positive effects of the child labor regulation concentrate on the less developed regions.

Table 7 shows the same labor market results for women. We can see that the reform did not have an impact in any of the labor market variables for treated women. ${ }^{15}$ This result applies to both less and more developed regions. Since the reform did not have a positive effect on women educational attainment in less developed regions, the absence of labor market effects is as expected. In contrast, the absence of labor market effects in more developed regions is still surprising in view of the improved educational attainment in those regions. We believe that stereotypes against women working outside the home may have limited the effectiveness of the reform in these regions. Indeed, women in these cohorts still had very low labor force participation and employment rates. Indeed, in the mid-80's, activity rates of women in Spain were among the very lowest ones in the European context: activity rates were 38\% for Spanish women in 1987 (ages 15 to 64) while they were almost $80 \%$ for Danish women, 55\% for German women, 58\% for French women and $41 \%$ for Italian women (CES, 2016).

\section{Robustness checks}

This section provides three additional robustness tests.

\footnotetext{
${ }^{15}$ Although the coefficient for the probability of working in the construction sector is positive and significant at the $10 \%$ level for women in more developed regions, the p-value of the wild bootstrap procedure shows that this coefficient is not significant when adjusting by the small number of clusters.
} 
First, in Tables 8 and 9 we provide the results for a placebo experiment in which we analyze the impact of a fake reform in one pre-reform year as well as in one post-reform year. Thus, in Table 8 we estimate the results for a fake reform introduced in 1959. We keep only cohorts from 1957 to 1964 to exclude the cohorts affected by the true reform and estimate the same model explained above for the baseline results. We can see that the results are not significant, neither for men nor for women, for any of the two outcomes educational outcomes studied; ESL and dropouts. Similarly, in Table 9, we estimate the results of a fake reform in 1971 and include only post-reform cohorts from 1966 to 1976. Again, we see that the results are not significant for men/women for any of the two outcomes.

Second, taking into account that the cohort of 1965 was aged 15 at the time of the reform and it can be considered as partly affected by the reform (as shown above), we perform an additional robustness check in which we exclude the cohort of 1965 from the regressions. We can see in Table 10 that the results are relatively similar to our baseline results (reported in Table 1) again for both genders and both outcomes.

Finally, although it is not possible to estimate a regression discontinuity design with the LFS due to the low number of observations at the month-of-birth level, we perform a regression discontinuity model for the educational outcomes using the 2001 census data. Table A2 reports results of these estimations. As before, the dependent variable is the probability of being an ESL or a dropout multiplied by 100 . The data is now collapsed at the level of month and year of birth and the regressions include cohort (year of birth) and month-of-birth fixed effects. "Treat" are individuals born in months 1 to 5 and those individuals born in months 8 to 12 form the control group. In the first four columns we do not exclude any cohort so that the "Post" variable is one for those individuals that turn 14 immediately after the reform: those born after month 6 (June) of the 1966 cohort. However, the RD design might entail some estimation caveats because, as explained above, the law was passed in March (towards the end of the educational year which finishes in June) so that is not clear the degree of enforcement of the law during this first year. Furthermore, there are a proportion of students subject to grade retention and, as the RD identification strategy is based on month-ofbirth cohort, there might be a potential problem of misclassification of individuals in the treatment group. Therefore, in order to try to minimize these potential sources of biases in the RD design, in the last four columns of Table A2 we estimate the same model but excluding the cohort of 1966 which is the cohort that turns 14 in the year of the reform (following our baseline regressions with the diff-diff model). The regressions in columns 1, 2, 5 and 6 include a linear pre-reform and a linear post-reform trend while the models in columns 3, 4, 7 and 8 include both a linear and quadratic pre and post reform trend. As we can see in the Table, the coefficient (Treat*Post) that captures the impact of the reform on ESL and on dropouts is always negative and highly significant (except for ESL in the specification with linear trends and all cohorts included). Furthermore, as expected the coefficients are even higher when excluding the 1966 cohort from 
the RD design. Therefore, we believe that the results of this additional regression discontinuity method provide strong evidence of the robustness of our estimates.

\section{Conclusion}

In this paper, we have explored the effects of a child labor regulation reform introduced in Spain in 1980 that increased the legal working age from 14 to 16, while the school-leaving age remained at the age of 14. Before the reform, children born in the first months of the year turned 14 and were legally able to work before finishing compulsory education. The labor market reform of 1980 eliminated the difference in alternatives available to individuals born at different times of the year: they would all have attained compulsory education by the time they reached the legal age to work.

Exploiting this difference in incentives, we have shown that the increase in the legal working age reduced the number of ESLs (not finishing compulsory education) by $7.6 \%$ for men and by $11 \%$ for women born at the beginning of the year. At the same time, the reform also decreased the number of individuals born in the first months of the year that did not finish some level of post-compulsory education (dropouts) by $3.3 \%$ for men and by $2.7 \%$ for women.

Regarding labor market outcomes, we find that the reform had a different impact on the labor market outcomes of men and women. In the case of men, it increased the probability of being employed as well as wages and it also affected the composition of employment, increasing the skill level of workers and improving employment conditions, with a lower incidence of working accidents. In contrast, in the case of women, we only find a reduction in working accidents as a result of the increase in educational attainment while we do not report any significant increase in employment or wages or any improvement in the skill level of the jobs. We next divide the 17 Autonomous Communities into two groups according to the social development of each region to analyze the existence of heterogeneous results across Spanish regions. Doing this, we find that the positive effects in education and employment of the child labor regulation concentrate in less developed regions for the case of men. In the case of women educational improvements are concentrated in more developed regions while there is no long-term labor market effect in any of the two types of regions. We believe that this last result is due to other potentially stronger, limitations or incentives that did not change with the reform (such as stereotypes regarding women's employment).

Overall, our results suggest that raising and enforcing working age regulations can be a valid and less costly alternative to increasing the school leaving age in countries with levels of development similar to those of Spain in 1980. In particular, as we mentioned in the introduction, countries where the subsistence of the family relies on child labor may not benefit much from child labor regulations because these rules will be difficult to enforce. In contrast, we have shown that changes to the statutory minimum age to work can 
improve educational and labor outcomes when temporal inconsistencies drive the educational decisions made by the young. We have also seen that the departing socioeconomic environment may play a crucial role in the success of this policy. Stereotypes against women working outside the home could, for example, jeopardize any long-term labor market effects of child labor regulation as a result of increases in female educational attainment. Also, at times of economic prosperity, it is sometimes possible for young men to earn higher wages as unskilled workers than in a job requiring minimum skills. This provides a powerful incentive to quit school that is not affected by the reform. 


\section{REFERENCES}

Acemoglu, D. and Angrist, J. 2000. "How large are human-capital externalities? Evidence from Compulsory schooling laws”, NBER Macroeconomics Annual, 15, pp.9-59.

Alonso-Colmenares, M.D., Lara, A., Arévalo, R. y J. Ruiz-Castillo. (1999): "La Encuesta de Presupuestos Familiares de 1980-81”. Mimeo.

Anderberg, D. and Zhu, Y. 2014. "What a difference a term makes: the effect of educational attainment on marital outcomes in the UK", Journal of Population Economics, 27(2), pp.387-419.

Bellés, C., Jiménez, S. and J. Vall. 2015. "The unintended effects of increasing the legal working age on family behavior". FEDEA working paper 2015-09.

Bellés, C., Cabrales, A., Jimenez-Martin, S. and J. Vall. 2017. "Mothers' care: reversing early childhood health shocks through parental investments".

Available at: http://www.ucl.ac.uk/ uctpcab/research/parental.pdf

Beltrán, F. and Gallego, D., 2015. "Gender discrimination in mid-19 century Spain”, Cambridge Working Papers in Economic and Social History No.23.

Black, S.E., Devereux, P.J. and Salvanes, K.G., 2008. "Staying in the classroom and out of the maternity ward? The effect of compulsory schooling laws on teenage births". The Economic Journal, 118, pp. 10251054.

Bound, J. and Jaeger, D., 2000. "Do compulsory school attendance laws alone explain the association between quarter of birth and earnings?" Worker Well-being, 19, pp.83-108.

Brunello, G., Weber, G., Weiss, C., 2015. "Books are forever: early life conditions, education and lifetime earnings". The Economic Journal, 127 (600), pp.271-296.

Buckles, K.S., and Hungerman, M., 2013. "Season of birth and later outcomes: Old questions, new answers", Review of Economics and Statistics, 95(3), pp.711-724.

Cadena, B. C. and B. J. Keys. 2015. "Human Capital and the Lifetime Costs of Impatience", American Economic Journal: Economic Policy. Vol. 7, no. 3, pp. 126-53.

Cameron, A.C., Miller, D.L. 2015. “A Practitioner's Guide to Cluster-Robust Inference”, The Journal of Human Resources, 50(2), pp.317-372.

Clark, D. and Royer, H., 2013. "The Effect of Education on Adult Mortality and Health: Evidence from Britain", American Economic Review, 103(6), pp.2087-2120.

Consejo Económico y Social (CES), 2016. "La Participación Laboral de las Mujeres en España", http://www.ces.es/documents/10180/3557409/Inf0516.pdf

Dee, T. S., 2004. “Are there civic returns to education?”, Journal of Public Economics, 88(9-10), pp.16971720.

Dickson, M. and Harmon, C., 2011. "Economic returns to education: What We Know, What We Don't Know, and Where We Are Going-Some brief pointers", Economics of Education Review, 30(6), pp.11181122. 
Edmonds, E.V. and Shrestha, M., 2012. "The Impact of Minimum Age of Employment Regulation on Child Labor and Schooling: Evidence from Unicef MICS countries”, NBER Working Paper 18623.

Felgueroso, F., Gutiérrez-Domènech, M. and Jiménez-Martín, S., 2014. "Dropout trends and educational reforms: the role of the LOGSE in Spain”, IZA Journal of Labor Policy, 3(1), pp.1-24.

Grenet, J. 2013. "Is extending compulsory schooling alone enough to raise earnings? Evidence from French and British compulsory schooling laws”. The Scandinavian Journal of Economics, 115(1), pp.176-210.

Goldin, C. and Katz, L.F., 2011. "Mass Secondary Schooling and the State: The Role of State Compulsion in the High School Movement". In Understanding Long-Run Economic Growth, edited by D. Costa and N. Lamoreaux. Chicago: University of Chicago Press.

Haveman, R.H. and Wolfe, B.L., 1984. "Schooling and Economic Well-Being: The Role of Nonmarket Effects", Journal of Human Resources, 19(3), pp.377-407.

Hainmueller, J. 2012. Entropy balancing for causal effects: A multivariate reweighting method to produce balanced samples in observational studies. Political Analysis, 20(1), pp.25-46.

Heckman, J., Humphries, J.E., Veramendi, G. and Urzúa, S., 2014. "Education, health and wages", NBER Working Paper 19971. Cambridge, Massachusetts: National Bureau of Economic Research.

Lleras-Muney, A. and Shertzer, A., 2015. "Did the Americanization Movement Succeed? An Evaluation of the Effect of English-Only and Compulsory Schooling Laws on Immigrants", American Economic Journal: Economic Policy, 7(3), pp.258-290.

Lleras-Muney, A., 2005. "The Relationship between Education and Adult Mortality in the U.S.", Review of Economic Studies, 72(1), pp.189-221.

Lleras-Muney, A., 2002. "Were Compulsory Attendance and Child Labor Laws Effective? An Analysis from 1915 to 1939". Journal of Law and Economics, 45(2), pp.401-35.

Lochner, L., 2004. "Education, Work, And Crime: A Human Capital Approach", International Economic Review, 45(3), pp.811-843.

Mackinnon, J.G., Webb, M.D. 2016a. "Wild Bootstrap Inference for Wildly Different Cluster Sizes", Journal of Applied Econometrics, 32(2), pp.233-254.

Mackinnon, J.G., Webb, M.D. 2016b. "Difference-in-difference inference with few treated clusters", Queen's Economics Department Working Paper 1355. Queen's University, Kingston, Ontario, Canada.

Milligan, K., Moretti, E. and Oreopoulos, P., 2004. "Does education improve citizenship? Evidence from the United States and the United Kingdom”, Journal of Public Economics, 88(9-10), pp.1667-1695.

O’Donoghue, T. and Rabin, M., 1999. "Doing it now or later", American Economic Review, 89(1), pp.103124.

Oreopoulos, P., 2006. "The compelling effects of compulsory schooling: evidence from Canada", Canadian Journal of Economics, 39(1), pp.22-52. 
Oreopoulos, P., and Salvanes, K.G., 2011. "Priceless: The Nonpecuniary benefits of schooling”. Journal of Economic Perspectives, 25 (1), pp. 159-184.

Romano J.P. and M. Wolf. 2005a. "Exact and Approximate Stepdown Methods for Multiple Hypothesis Testing”. Journal of the American Statistical Association 100(469): 94-108.

Romano J.P. and M. Wolf. 2005b. "Stepwise Multiple Testing as Formalized Data Snooping". Econometrica 73(4): 1237-1282.

Romano J.P. and M. Wolf. 2016. "Efficient computation of adjusted p-values for resampling-based stepdown multiple testing". Statistics and Probability Letters 113: 38-40.

Tena, J., 1981. “El analfabetismo en España, hoy”. Revista de Educación, 268, pp. 91-297. 


\section{FIGURES AND TABLES}

Figure 1. Labor force attachment and age of entry distribution of affected cohorts.

Labor force participation rate and employment rate at ages 14 and 15
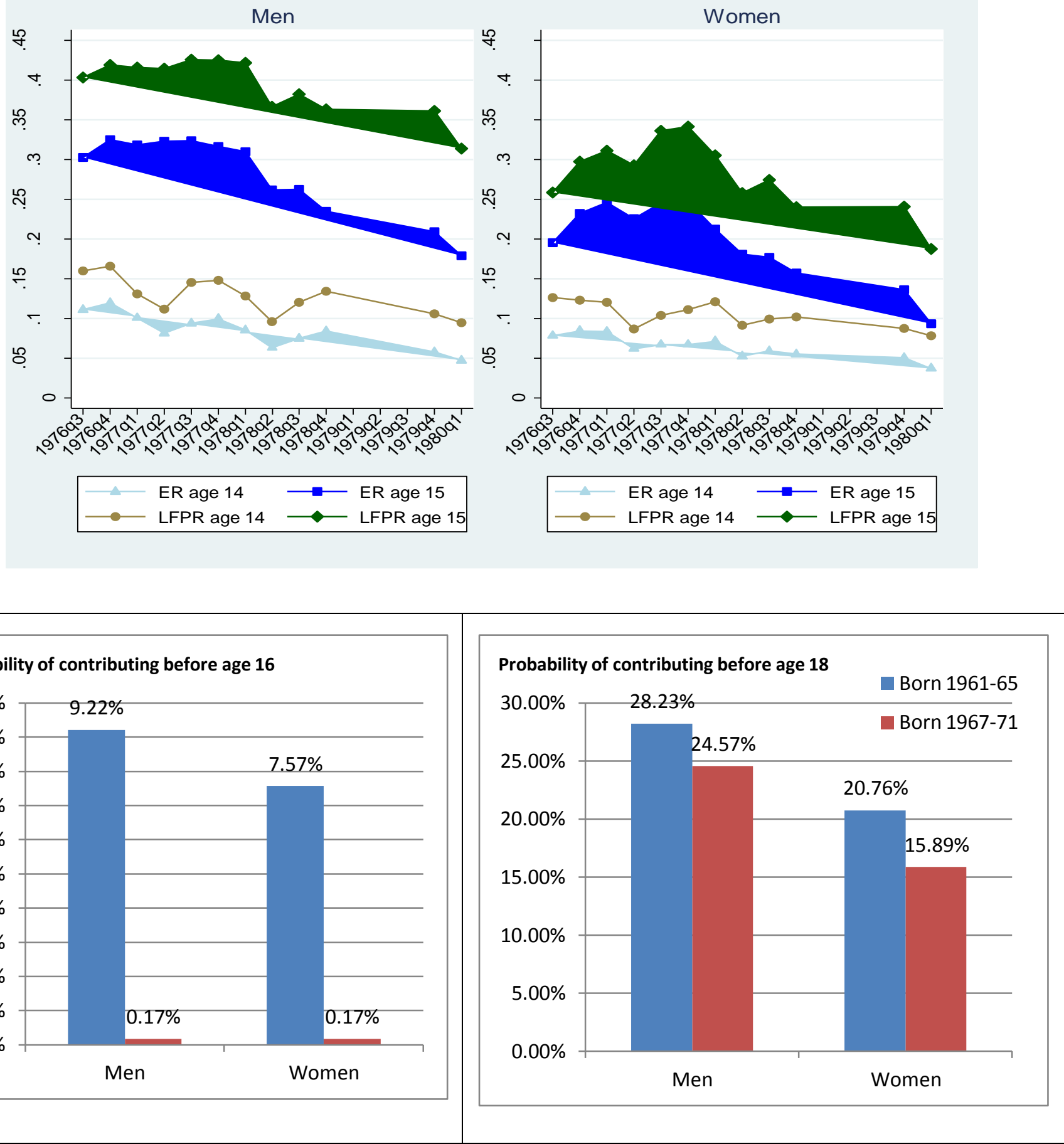

Source: Spanish Labor force survey for the top panels and MCVL for the bottom ones. 
Figure 2. Education attainment as a function of the degree of impatience before and after the reform when $s<y_{0}<y_{1}<y_{2}$

Treated individuals before the reform:

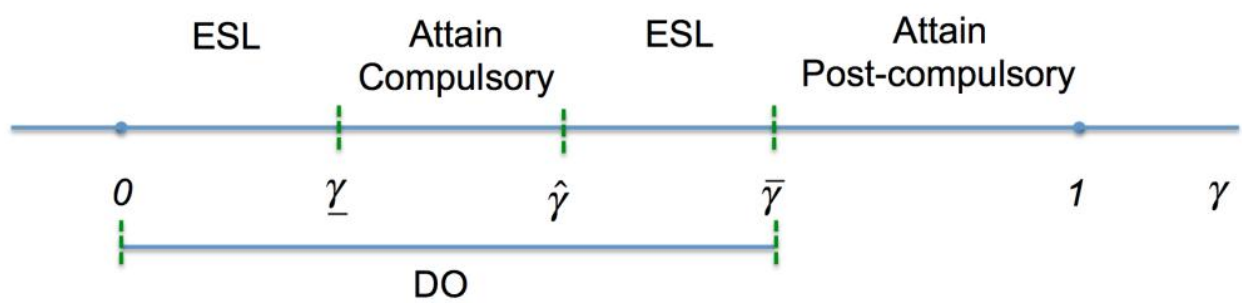

Treated individuals after the reform and non-treated individuals:

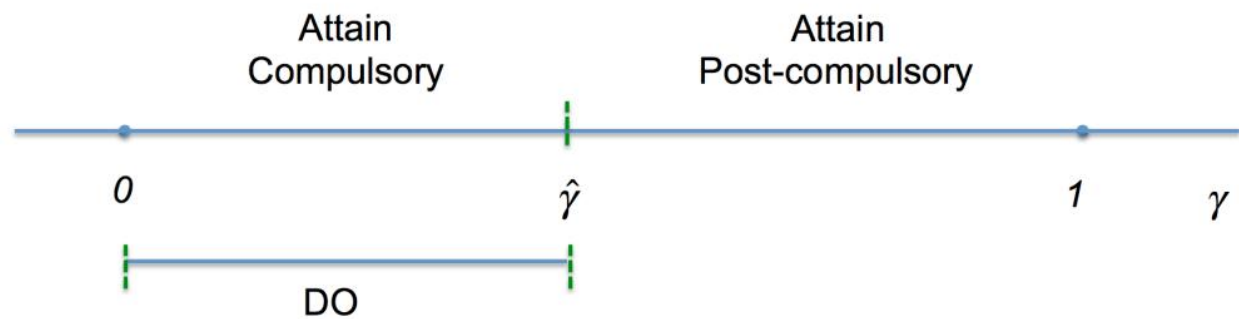

Figure 3. Probability of being an early school leaver (ESL) and a high-school dropout (DO).
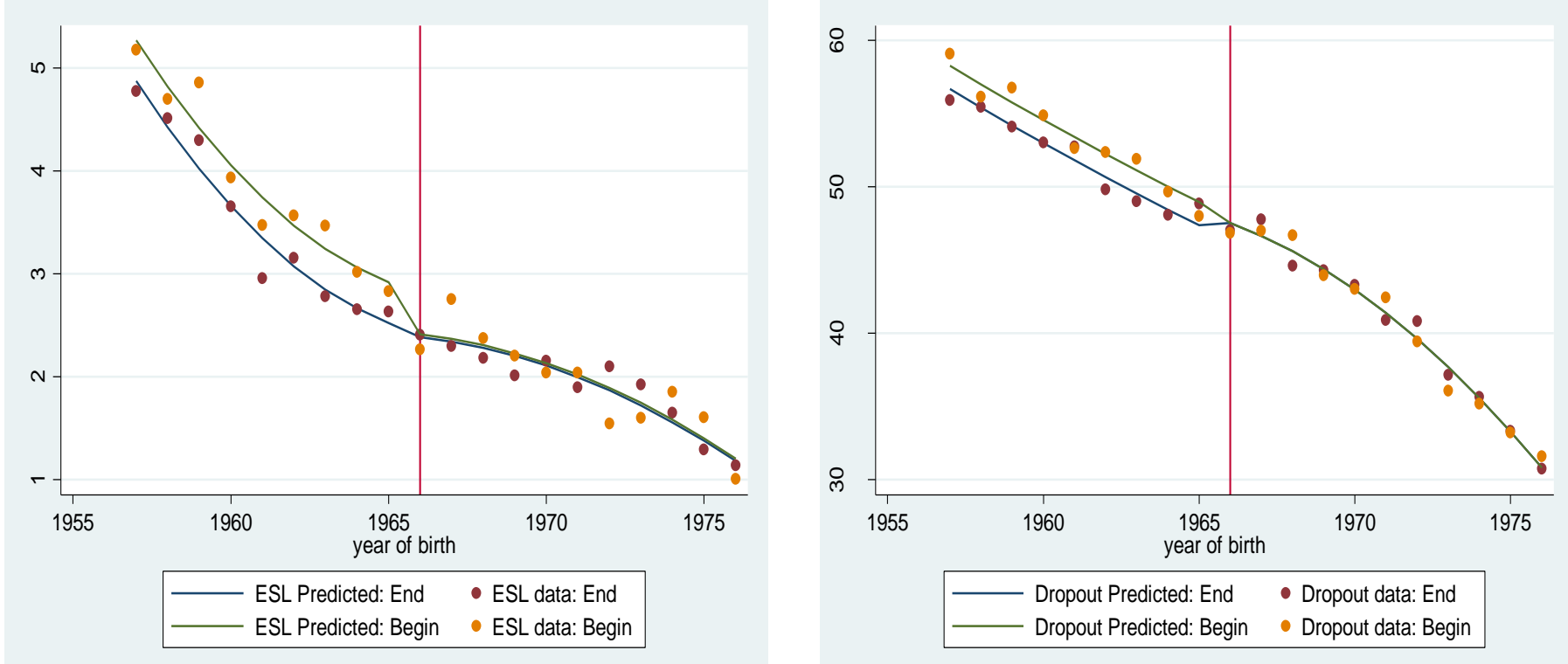

Note: The predictions are from a regression of the probability of being an ESL with linear and quadratic trends and the dummies to identify the effect of the policy. "Begin" are individuals born in months 3, 4 and 5 and "end" are those born in months 8,9 and 10 .

Source: Labor Force Survey (2000-2013). 
Table 1. Early school leaver and high-school dropouts.

\begin{tabular}{|c|c|c|c|c|}
\hline & \multicolumn{2}{|c|}{ Men } & \multicolumn{2}{|c|}{ Women } \\
\hline & ESL & DROPOUT & ESL & DROPOUT \\
\hline \multirow[t]{3}{*}{ Treat } & $2.061^{* *}$ & 1.344 & 1.430* & 0.977 \\
\hline & (0.919) & (1.301) & $(0.702)$ & $(0.768)$ \\
\hline & {$[0.07]$} & [0.35] & {$[0.06]$} & [0.24] \\
\hline \multirow[t]{3}{*}{ Treat*Post } & $-1.238^{*}$ & $-1.630^{*}$ & $-1.412^{* *}$ & $-1.226^{*}$ \\
\hline & $(0.675)$ & $(0.822)$ & $(0.495)$ & $(0.620)$ \\
\hline & {$[0.13]$} & [0.11] & {$[0.02]$} & [0.09] \\
\hline \multirow[t]{3}{*}{ Ur } & $-21.412^{* *}$ & 4.273 & $-35.394 * * *$ & 4.983 \\
\hline & $(8.414)$ & (9.365) & $(10.233)$ & (11.590) \\
\hline & {$[0.03]$} & [0.68] & {$[0.01]$} & {$[0.68]$} \\
\hline Region FE & $x$ & $x$ & $x$ & $x$ \\
\hline Cohort FE & $x$ & $x$ & $x$ & $x$ \\
\hline Time FE & $x$ & $x$ & $x$ & $x$ \\
\hline Time FE*Treat & $x$ & $x$ & $x$ & $x$ \\
\hline Observations & 112,217 & 112,217 & 116,375 & 116,375 \\
\hline R-squared & 0.055 & 0.040 & 0.077 & 0.070 \\
\hline
\end{tabular}

Robust standard errors in parentheses

$* * * p<0.01, * * p<0.05, * p<0.1$

Note: The dependent variable is the probability of being an ESL or a dropout multiplied by 100. Regressions include the unemployment rate of the region, and fixed effects for the 17 regions (autonomous communities in Spain), cohorts and time fixed effects as well as time fixed effects interacted with treatment. "Treat" are individuals born in months 3, 4, 5 and the control group are those born in months 8, 9, 10. Cohorts 19571976. Robust standard errors clustered at the cohort level in parentheses and p-values of the wild bootstrap procedure in brackets. Source: Labor Force Survey (2000-2013).

Table 2. Probability of having studied at the university level.

\begin{tabular}{lcc}
\hline & Men & Women \\
\hline Treat & & -0.424 \\
& -0.488 & $(0.653)$ \\
Treat*post & $(0.733)$ & {$[0.59]$} \\
& {$[0.47]$} & 0.821 \\
& $1.287^{* *}$ & $(0.507)$ \\
Ur & $(0.567)$ & {$[0.13]$} \\
& {$[0.03]$} & $-23.477^{* * *}$ \\
& $-18.172^{* * *}$ & $(5.297)$ \\
Region FE & $(6.103)$ & {$[0.00]$} \\
Cohort FE & {$[0.02]$} & $\mathrm{X}$ \\
Time FE & & $\mathrm{X}$ \\
Time FE*Treat & $\mathrm{X}$ & $\mathrm{X}$ \\
Observations & $\mathrm{X}$ & $\mathrm{X}$ \\
R-squared & $\mathrm{X}$ & 116,375 \\
\hline
\end{tabular}

Robust standard errors in parentheses

$* * * \mathrm{p}<0.01, * * \mathrm{p}<0.05, * \mathrm{p}<0.1$

Note: The dependent variable is the probability of having studied at the university level (at least three courses passed of any university degree) multiplied by 100. Regressions include the unemployment rate of the region, and fixed effects for the 17 regions (autonomous communities in Spain), cohorts and time fixed effects as well as time fixed effects interacted with treatment. "Treat" are individuals born in months $3,4,5$ and the control group are those born in months 8, 9, 10. Cohorts 1957-1976. Robust standard errors clustered at the cohort level in parentheses and pvalues of the wild bootstrap procedure in brackets. Source: Labor Force Survey (2000-2013). 
Table 3. Employment Outcomes.

\begin{tabular}{|c|c|c|c|c|c|}
\hline \multicolumn{6}{|l|}{ PANEL A: MEN } \\
\hline & Employ & Construct & Low Skill & Inactive & Wages (in In) \\
\hline \multirow[t]{3}{*}{ Treat } & $-2.377^{* * *}$ & $-1.954 * * *$ & -1.008 & 0.417 & -0.046 \\
\hline & $(0.687)$ & $(0.651)$ & $(1.074)$ & $(0.589)$ & $(0.060)$ \\
\hline & {$[0.00]$} & {$[0.02]$} & {$[0.34]$} & {$[0.48]$} & {$[0.17]$} \\
\hline \multirow[t]{3}{*}{ Treat*Post } & $0.597^{*}$ & $-0.748 *$ & $-1.707^{*}$ & -0.048 & $0.050 *$ \\
\hline & $(0.288)$ & $(0.357)$ & $(0.921)$ & $(0.361)$ & $(0.026)$ \\
\hline & [0.08] & {$[0.06]$} & {$[0.11]$} & {$[0.96]$} & [0.06] \\
\hline \multirow[t]{3}{*}{ Ur } & -10.735 & 3.619 & 10.993 & 1.090 & 0.093 \\
\hline & $(8.021)$ & $(4.601)$ & $(7.275)$ & $(5.346)$ & $(0.558)$ \\
\hline & {$[0.21]$} & {$[0.45]$} & {$[0.13]$} & [0.77] & [0.90] \\
\hline Obs & 109,055 & 91,065 & 91,065 & 109,055 & 23,692 \\
\hline \multicolumn{6}{|c|}{ PANEL B: WOMEN } \\
\hline \multirow[t]{3}{*}{ Treat } & -1.302 & 0.189 & -0.463 & -0.029 & -0.074 \\
\hline & $(0.862)$ & $(0.211)$ & $(0.813)$ & $(0.921)$ & $(0.080)$ \\
\hline & [0.17] & [0.33] & {$[0.62]$} & {$[0.10]$} & {$[0.17]$} \\
\hline \multirow[t]{3}{*}{ Treat*Post } & 0.922 & 0.079 & -0.139 & -1.081 & -0.019 \\
\hline & $(0.637)$ & (0.189) & $(0.650)$ & $(0.638)$ & $(0.042)$ \\
\hline & {$[0.16]$} & {$[0.00]$} & {$[0.78]$} & [0.09] & [0.73] \\
\hline \multirow[t]{3}{*}{ Ur } & -11.389 & $6.175^{* * *}$ & -3.438 & -5.286 & 0.095 \\
\hline & (7.175) & $(1.888)$ & (5.794) & (6.573) & $(0.548)$ \\
\hline & [0.18] & {$[0.00]$} & {$[0.53]$} & {$[0.46]$} & {$[0.78]$} \\
\hline Obs & 113,396 & 69,022 & 69,022 & 113,396 & 21,936 \\
\hline Cohort FE & $x$ & $x$ & $x$ & $x$ & $x$ \\
\hline Time FE & $x$ & $x$ & $x$ & $x$ & $x$ \\
\hline Time FE*Treat & $x$ & $x$ & $x$ & $x$ & $x$ \\
\hline
\end{tabular}

Robust standard errors in parentheses

$* * * p<0.01, * * p<0.05, * p<0.1$

Note: The dependent variable is the probability of being employed, working in the construction sector, working in a low-skilled job or being inactive multiplied by 100. In the last column the dependent variable is the $\ln$ (wages) for those that report a positive wage. Regressions include cohort, region and time fixed effects as well as time-by-treatment fixed effects. "Treated" are individuals born in months 3 , 4 and 5 and "control" are those born in months 8, 9 and 10. Cohorts included: 1957-1976. Robust standard errors clustered at the cohort level in parentheses and p-values of the wild bootstrap procedure in brackets. Source: Labor Force Survey (2000-2013) \& EU-SILC for wages (2004 to 2015). 
Table 4. Workplace Accidents by Type of Accident.

\begin{tabular}{lcccc}
\hline & \multicolumn{2}{c}{ Men } & \multicolumn{3}{c}{ Women } \\
\hline Treat & Dead & Total & Dead & Total \\
& 0.006 & $0.459^{*}$ & 0.000 & 0.064 \\
& $(0.005)$ & $(0.253)$ & $(0.001)$ & $(0.056)$ \\
Treat*Post & {$[0.22]$} & {$[0.10]$} & {$[0.79]$} & {$[0.29]$} \\
& -0.004 & $-0.657^{* *}$ & 0.000 & $-0.275^{* *}$ \\
& $(0.006)$ & $(0.298)$ & $(0.002)$ & $(0.116)$ \\
Region FE & {$[0.38]$} & {$[0.05]$} & {$[0.39]$} & {$[0.05]$} \\
Cohort FE & $\mathrm{X}$ & $\mathrm{X}$ & $\mathrm{X}$ & $\mathrm{X}$ \\
Obs & $\mathrm{X}$ & $\mathrm{X}$ & $\mathrm{X}$ & $\mathrm{X}$ \\
$\mathrm{R}$-squared & 408 & 408 & 408 & 408 \\
\hline
\end{tabular}

Robust standard errors in parentheses

$* * * \mathrm{p}<0.01, * * \mathrm{p}<0.05, * \mathrm{p}<0.1$

Note: The dependent variable is the number of individuals that suffer from a workplace accident for each cohort and treatment status divided by the number of individuals born in each cohort and treatment status multiplied by 1000. Regressions include region and cohort fixed effects. "Treated" are individuals born in months 3, 4 and 5 and "control" are those born in months 8, 9 and 10. Cohorts included; 1960-1972 (ages 2841 in 1988-2013). Robust standard errors clustered at the cohort level in parentheses and p-values of the wild bootstrap procedure in brackets. Source: Workplace accident registries (1988-2013) and number of individuals born in each cohort from birth registries.

Table 5. Heterogeneity of results. Education outcomes by type of region.

\begin{tabular}{|c|c|c|c|c|c|c|c|c|}
\hline & \multicolumn{4}{|c|}{ Men } & \multicolumn{4}{|c|}{ Women } \\
\hline & \multicolumn{2}{|c|}{ More Developed } & \multicolumn{2}{|c|}{ Less Developed } & \multicolumn{2}{|c|}{ More Developed } & \multicolumn{2}{|c|}{ Less Developed } \\
\hline & ESL & DROPOUT & ESL & DROPOUT & ESL & DROPOUT & ESL & DROPOUT \\
\hline \multirow[t]{3}{*}{ Treat } & $1.707^{*}$ & 0.954 & $2.222^{*}$ & 1.570 & 1.232 & -0.538 & $1.541^{*}$ & 1.924 \\
\hline & $(0.880)$ & (1.474) & (1.109) & (1.478) & (1.006) & (1.426) & $(0.782)$ & (1.194) \\
\hline & {$[0.08]$} & {$[0.48]$} & {$[0.1]$} & [0.38] & {$[0.2]$} & {$[0.75]$} & [0.07] & [0.10] \\
\hline \multirow[t]{3}{*}{ Treat*Post } & -0.180 & 0.316 & $-1.827^{* *}$ & $-2.791^{* *}$ & $-1.779 * * *$ & $-2.170^{*}$ & $-1.207^{*}$ & -0.724 \\
\hline & $(0.633)$ & $(0.876)$ & $(0.848)$ & $(0.983)$ & (0.572) & (1.079) & (0.623) & $(1.066)$ \\
\hline & {$[0.68]$} & [0.71] & {$[0.07]$} & [0.01] & [0.02] & {$[0.09]$} & {$[0.09]$} & [0.55] \\
\hline \multirow[t]{3}{*}{ Ur } & 0.348 & -3.573 & $-20.385^{* *}$ & 14.142 & $-21.700^{*}$ & -12.588 & $-29.694 * * *$ & $25.848^{* *}$ \\
\hline & $(10.956)$ & (15.631) & (9.632) & (9.018) & (10.888) & $(18.063)$ & (9.554) & $(9.236)$ \\
\hline & [0.98] & {$[0.75]$} & {$[0.06]$} & [0.14] & {$[0.07]$} & {$[0.5]$} & [0.02] & [0.01] \\
\hline Region FE & $x$ & $x$ & $x$ & $x$ & $x$ & $x$ & $x$ & $x$ \\
\hline Cohort FE & $x$ & $x$ & $x$ & $x$ & $x$ & $x$ & $x$ & $x$ \\
\hline Time FE & $\mathrm{x}$ & $\mathrm{x}$ & $x$ & $x$ & $\mathrm{x}$ & $\mathrm{x}$ & $\mathrm{x}$ & $\mathrm{x}$ \\
\hline Time FE*Treat & $x$ & $x$ & $\mathrm{x}$ & $x$ & $\mathrm{x}$ & $\mathrm{x}$ & $\mathrm{x}$ & $\mathrm{x}$ \\
\hline Observations & 40,922 & 40,922 & 71,295 & 71,295 & 42,817 & 42,817 & 73,558 & 73,558 \\
\hline R-squared & 0.057 & 0.044 & 0.047 & 0.024 & 0.072 & 0.065 & 0.073 & 0.059 \\
\hline
\end{tabular}

Robust standard errors in parentheses

$* * * \mathrm{p}<0.01, * * \mathrm{p}<0.05, * \mathrm{p}<0.1$

Note: The dependent variable is the probability of being an ESL or a dropout multiplied by 100. Regressions include the unemployment rate of the region, and fixed effects for regions, cohorts and time as well as time fixed effects interacted with treatment. "Treat" are individuals born in months 3, 4, 5 and the control group are those born in months 8, 9,10. Cohorts 1957-1976. Robust standard errors clustered at the cohort level in parentheses and p-values of the wild bootstrap procedure in brackets. More developed regions include Madrid, Basque Country, Cantabria, Canarias, Catalunya, Balearic Islands, Rioja, Asturias and Navarra. Source: Labor Force Survey (2000-2013). 
Table 6. Heterogeneity of results. Employment outcomes by type of region. Men.

\begin{tabular}{|c|c|c|c|c|c|}
\hline \multicolumn{6}{|c|}{ PANEL A: MORE DEVELOPED REGIONS } \\
\hline & Employ & Construct & Low Skill & Inactive & Wages (in In) \\
\hline \multirow[t]{3}{*}{ Treat } & $-1.918 * *$ & -1.368 & -0.520 & 0.108 & -0.102 \\
\hline & $(0.753)$ & $(0.984)$ & $(1.332)$ & $(0.658)$ & $(0.075)$ \\
\hline & {$[0.01]$} & {$[0.17]$} & {$[0.70]$} & {$[0.82]$} & {$[0.34]$} \\
\hline \multirow[t]{3}{*}{ Treat*Post } & -0.793 & -0.036 & -0.070 & 0.361 & -0.001 \\
\hline & $(0.610)$ & $(0.702)$ & $(1.342)$ & $(0.517)$ & $(0.058)$ \\
\hline & {$[0.25]$} & {$[0.88]$} & [0.87] & [0.57] & {$[0.12]$} \\
\hline \multirow[t]{3}{*}{ Ur } & -14.837 & -0.289 & $43.252 * * *$ & -1.301 & 0.590 \\
\hline & $(11.535)$ & $(11.900)$ & $(13.868)$ & $(10.913)$ & $(0.732)$ \\
\hline & {$[0.22]$} & [0.97] & {$[0.01]$} & [0.89] & {$[0.53]$} \\
\hline Obs & 39,768 & 34,129 & 34,129 & 39,768 & 11,340 \\
\hline \multicolumn{6}{|c|}{ PANEL B: LESS DEVELOPED REGIONS } \\
\hline \multirow[t]{3}{*}{ Treat } & $-2.620 * *$ & $-2.331 * * *$ & -1.372 & 0.582 & -0.011 \\
\hline & $(0.956)$ & $(0.806)$ & (1.364) & $(0.804)$ & $(0.090)$ \\
\hline & {$[0.02]$} & {$[0.01]$} & [0.35] & {$[0.45]$} & {$[0.00]$} \\
\hline \multirow[t]{3}{*}{ Treat*Post } & $1.349 * *$ & $-1.198 * *$ & $-2.728 * *$ & -0.264 & $0.100 *$ \\
\hline & $(0.630)$ & $(0.558)$ & $(1.090)$ & $(0.511)$ & $(0.052)$ \\
\hline & [0.04] & [0.03] & {$[0.03]$} & {$[0.68]$} & {$[0.14]$} \\
\hline \multirow[t]{3}{*}{ Ur } & -8.855 & 7.347 & -2.136 & 2.228 & -0.169 \\
\hline & $(10.129)$ & $(6.138)$ & (7.241) & $(5.712)$ & $(0.850)$ \\
\hline & [0.43] & {$[0.32]$} & {$[0.75]$} & {$[0.7]$} & {$[0.88]$} \\
\hline Obs & 69,287 & 56,936 & 56,936 & 69,287 & 12,352 \\
\hline Cohort FE & $x$ & $x$ & $x$ & $x$ & $x$ \\
\hline Time FE & $x$ & $x$ & $x$ & $x$ & $x$ \\
\hline Time FE*Treat & $x$ & $x$ & $x$ & $x$ & $x$ \\
\hline
\end{tabular}

Robust standard errors in parentheses

$* * * p<0.01, * * p<0.05, * p<0.1$

Note: The dependent variable is the probability of being employed, working in the construction sector, working in a low-skilled job or being inactive multiplied by 100. In the last column the dependent variable is the $\ln$ (wages) for those that report a positive wage. Regressions include cohort, region and time fixed effects as well as time-by-treatment fixed effects. "Treated" are individuals born in months 3,4 and 5 and "control" are those born in months 8, 9 and 10. Cohorts included: 1957-1976. Robust standard errors clustered at the cohort level in parentheses and p-values of the wild bootstrap procedure in brackets. More developed regions include Madrid, Basque Country, Cantabria, Canarias, Catalunya, Balearic Islands, Rioja, Asturias and Navarra. Source: Labor Force Survey (2000-2013) \& EU-SILC for wages (2004 to 2015). 
Table 7. Heterogeneity of results. Employment outcomes by type of region. Women.

\begin{tabular}{|c|c|c|c|c|c|}
\hline \multicolumn{6}{|c|}{ PANEL A: MORE DEVELOPED REGIONS } \\
\hline & Employ & Construct & Low Skill & Inactive & Wages (in In) \\
\hline \multirow[t]{3}{*}{ Treat } & $-2.637^{* *}$ & -0.582 & 0.957 & 1.751 & -0.090 \\
\hline & $(1.231)$ & $(0.366)$ & $(1.903)$ & $(1.303)$ & $(0.127)$ \\
\hline & {$[0.05]$} & {$[0.08]$} & {$[0.63]$} & [0.19] & {$[0.49]$} \\
\hline \multirow[t]{3}{*}{ Treat*Post } & 1.815 & $0.579 *$ & -0.376 & -1.086 & -0.084 \\
\hline & $(1.315)$ & $(0.298)$ & $(1.009)$ & $(1.124)$ & $(0.067)$ \\
\hline & {$[0.25]$} & {$[0.12]$} & {$[0.73]$} & {$[0.44]$} & {$[0.24]$} \\
\hline \multirow[t]{3}{*}{ Ur } & -31.735 & $11.480 * * *$ & -1.947 & 17.437 & 0.693 \\
\hline & $(18.379)$ & $(2.866)$ & $(13.707)$ & $(12.637)$ & $(0.870)$ \\
\hline & [0.11] & {$[0.00]$} & {$[0.79]$} & [0.19] & {$[0.75]$} \\
\hline Obs & 41,531 & 28,031 & 28,031 & 41,531 & 10,462 \\
\hline \multicolumn{6}{|c|}{ PANEL B: LESS DEVELOPED REGIONS } \\
\hline \multirow[t]{3}{*}{ Treat } & -0.563 & $0.707^{* *}$ & -1.439 & -1.021 & -0.078 \\
\hline & $(0.960)$ & $(0.301)$ & $(1.520)$ & $(0.932)$ & $(0.088)$ \\
\hline & {$[0.57]$} & {$[0.02]$} & [0.32] & {$[0.29]$} & {$[0.14]$} \\
\hline \multirow[t]{3}{*}{ Treat*Post } & 0.365 & -0.250 & -0.007 & -1.045 & 0.049 \\
\hline & $(0.906)$ & $(0.256)$ & $(1.055)$ & $(0.831)$ & $(0.049)$ \\
\hline & {$[0.71]$} & {$[0.27]$} & {$[0.11]$} & {$[0.27]$} & {$[0.40]$} \\
\hline \multirow[t]{3}{*}{ Ur } & -5.674 & 2.750 & $-12.827^{*}$ & -10.716 & -0.750 \\
\hline & $(11.701)$ & $(1.730)$ & $(7.345)$ & (9.181) & $(0.788)$ \\
\hline & {$[0.63]$} & {$[0.12]$} & {$[0.14]$} & {$[0.28]$} & {$[0.41]$} \\
\hline Obs & 71,865 & 40,991 & 40,991 & 71,865 & 11,474 \\
\hline Cohort FE & $x$ & $x$ & $x$ & $x$ & $x$ \\
\hline Time FE & $x$ & $x$ & $x$ & $x$ & $x$ \\
\hline Time FE*Treat & $x$ & $x$ & $x$ & $x$ & $x$ \\
\hline
\end{tabular}

Robust standard errors in parentheses

$* * * \mathrm{p}<0.01, * * \mathrm{p}<0.05, * \mathrm{p}<0.1$

Note: The dependent variable is the probability of being employed, working in the construction sector, working in a low-skilled job or being inactive multiplied by 100. In the last column the dependent variable is the $\ln$ (wages) for those that report a positive wage. Regressions include cohort, region and time fixed effects as well as time-by-treatment fixed effects. "Treated" are individuals born in months 3 , 4 and 5 and "control" are those born in months 8, 9 and 10. Cohorts included: 1957-1976. Robust standard errors clustered at the cohort level in parentheses and p-values of the wild bootstrap procedure in brackets. More developed regions include Madrid, Basque Country, Cantabria, Canarias, Catalunya, Balearic Islands, Rioja, Asturias and Navarra. Source: Labor Force Survey (2000-2013) \& EU-SILC for wages (2004 to 2015). 
Table 8. Placebo tests. Fake policy for the cohort of 1959. Education outcomes.

\begin{tabular}{|c|c|c|c|c|}
\hline & \multicolumn{4}{|c|}{$\begin{array}{l}\text { Fake policy for the cohort of } 1959 \\
\text { (keep only observations until the cohort of 1965) }\end{array}$} \\
\hline & \multicolumn{2}{|c|}{ MEN } & \multicolumn{2}{|c|}{ WOMEN } \\
\hline & ESL & DROPOUT & ESL & DROPOUT \\
\hline \multirow[t]{3}{*}{ Treat } & 1.800 & 1.520 & $3.298 * *$ & 1.995 \\
\hline & $(2.074)$ & $(2.547)$ & (1.081) & $(1.732)$ \\
\hline & {$[0.41]$} & [0.52] & {$[0.00]$} & {$[0.27]$} \\
\hline \multirow[t]{3}{*}{ Treat*Post } & 1.105 & 0.935 & -0.080 & -0.592 \\
\hline & (1.976) & $(1.978)$ & (1.168) & $(0.505)$ \\
\hline & {$[0.58]$} & {$[0.78]$} & [0.92] & {$[0.40]$} \\
\hline \multirow[t]{3}{*}{ Ur } & $76.477^{* *}$ & 28.927 & $27.988^{*}$ & 42.712 \\
\hline & $(24.323)$ & (21.393) & (11.953) & $(28.152)$ \\
\hline & {$[0.09]$} & {$[0.10]$} & {$[0.00]$} & {$[0.42]$} \\
\hline Region FE & $x$ & $x$ & $x$ & $x$ \\
\hline Cohort FE & $x$ & $x$ & $x$ & $x$ \\
\hline Time FE & $x$ & $x$ & $x$ & $x$ \\
\hline Time FE*Treat & $x$ & $x$ & $x$ & $x$ \\
\hline Observations & 41,523 & 41,523 & 44,208 & 44,208 \\
\hline R-squared & 0.042 & 0.027 & 0.051 & 0.032 \\
\hline
\end{tabular}

Robust standard errors in parentheses

$* * * \mathrm{p}<0.01, * * \mathrm{p}<0.05, * \mathrm{p}<0.1$

Note: The dependent variable is the probability of being an ESL or a dropout multiplied by 100. Regressions include the unemployment rate of the region, and fixed effects for the 17 regions (autonomous communities in Spain), for cohorts and time as well as time fixed effects interacted with treatment. "Treat" are individuals born in months 3, 4 and 5 and the control group are those born in months 8, 9 and 10. Cohorts 1957-1964. Robust standard errors clustered at the cohort level in parentheses and p-values of the wild bootstrap procedure in brackets. Source: Labor Force Survey (2000-2013). 
Table 9. Placebo tests. Fake policy for the cohort of 1971. Education outcomes.

\begin{tabular}{|c|c|c|c|c|}
\hline & \multicolumn{4}{|c|}{$\begin{array}{c}\text { Fake policy for the cohort of } 1971 \\
\text { (keep only observations from the cohort of 1966) }\end{array}$} \\
\hline & \multicolumn{2}{|c|}{ MEN } & \multicolumn{2}{|c|}{ WOMEN } \\
\hline & ESL & DROPOUT & ESL & DROPOUT \\
\hline \multirow[t]{3}{*}{ Treat } & 0.599 & $-1.217^{*}$ & -0.831 & -0.104 \\
\hline & $(0.504)$ & $(0.555)$ & $(0.610)$ & $(0.820)$ \\
\hline & {$[0.26]$} & {$[0.04]$} & {$[0.24]$} & [0.94] \\
\hline \multirow[t]{3}{*}{ Treat*Post } & -0.762 & 0.290 & -0.429 & -1.141 \\
\hline & $(0.511)$ & (0.694) & $(0.528)$ & $(1.025)$ \\
\hline & {$[0.24]$} & {$[0.65]$} & {$[0.45]$} & {$[0.30]$} \\
\hline \multirow[t]{3}{*}{ Ur } & $-22.657^{* * *}$ & -27.765 & $-31.201 * * *$ & $-50.238 * *$ \\
\hline & $(2.956)$ & (16.639) & (5.478) & (16.725) \\
\hline & {$[0.00]$} & {$[0.26]$} & {$[0.00]$} & {$[0.04]$} \\
\hline Region FE & $x$ & $x$ & $x$ & $x$ \\
\hline Cohort FE & $x$ & $x$ & $x$ & $x$ \\
\hline Time FE & $x$ & $x$ & $x$ & $x$ \\
\hline Time FE*Treat & $x$ & $x$ & $x$ & $x$ \\
\hline Observations & 58,384 & 58,384 & 59,057 & 59,057 \\
\hline R-squared & 0.031 & 0.036 & 0.034 & 0.055 \\
\hline
\end{tabular}

Robust standard errors in parentheses

$* * * \mathrm{p}<0.01, * * \mathrm{p}<0.05, * \mathrm{p}<0.1$

Note: The dependent variable is the probability of being an ESL or a dropout multiplied by 100. Regressions include the unemployment rate of the region, and fixed effects for the 17 regions (autonomous communities in Spain), for cohorts and time as well as time fixed effects interacted with treatment. "Treat" are individuals born in months 3, 4 and 5 and the control group are those born in months 8, 9 and 10. Cohorts 1966-1976. Robust standard errors clustered at the cohort level in parentheses and p-values of the wild bootstrap procedure in brackets. Source: Labor Force Survey (2000-2013). 
Table 10. Robustness checks. Excluding the cohort of 1965 (partly treated).

\begin{tabular}{ccccc}
\hline & \multicolumn{3}{c}{ Men } & \multicolumn{3}{c}{ Women } \\
\hline Treat & ESL & DROPOUT & ESL & DROPOUT \\
& $2.287^{* *}$ & 1.949 & $1.406^{*}$ & 1.015 \\
& $(0.973)$ & $(1.249)$ & $(0.750)$ & $(0.811)$ \\
Treat*Post & {$[0.05]$} & {$[0.14]$} & {$[0.07]$} & {$[0.27]$} \\
& $-1.385^{*}$ & $-2.027^{* *}$ & $-1.484^{* *}$ & $-1.414^{* *}$ \\
& $(0.730)$ & $(0.802)$ & $(0.536)$ & $(0.613)$ \\
Ur & {$[0.12]$} & {$[0.03]$} & {$[0.02]$} & {$[0.04]$} \\
& $-20.962^{* *}$ & 4.941 & $-34.440^{* * *}$ & 7.154 \\
& $(8.365)$ & $(9.631)$ & $(10.015)$ & $(11.059)$ \\
Region FE & {$[0.00]$} & {$[0.63]$} & {$[0.01]$} & {$[0.5]$} \\
Cohort FE & $\mathrm{X}$ & $\mathrm{X}$ & $\mathrm{X}$ & $\mathrm{X}$ \\
Time FE & $\mathrm{X}$ & $\mathrm{X}$ & $\mathrm{X}$ & $\mathrm{X}$ \\
Time FE*Treat & $\mathrm{X}$ & $\mathrm{X}$ & $\mathrm{X}$ & $\mathrm{X}$ \\
Observations & 106,081 & 106,081 & 109,910 & $\mathrm{X}$ \\
R-squared & 0.056 & 0.040 & 0.079 & 0.071 \\
\hline
\end{tabular}

Robust standard errors in parentheses

$* * * \mathrm{p}<0.01, * * \mathrm{p}<0.05, * \mathrm{p}<0.1$

Note: The dependent variable is the probability of being an ESL or a dropout multiplied by 100. Regressions include the unemployment rate of the region, and fixed effects for the 17 regions, cohorts and time as well as time fixed effects interacted with treatment. "Treat" are individuals born in months 3, 4 and 5 and the control group are those born in months 8, 9 and 10. Cohorts 1957-1976 (excluding 1965 and 1966). Robust standard errors clustered at the cohort level in parentheses and p-values of the wild bootstrap procedure in brackets. Source: Labor Force Survey (2000-2013). 


\section{APPENDIX}

Figure A1. Incentives of individuals born at the beginning and end of the year before the reform.

Individuals born in January 1963: Pre-reform (aged 17 in 1980)

Calendar year 1977 (turns 14)

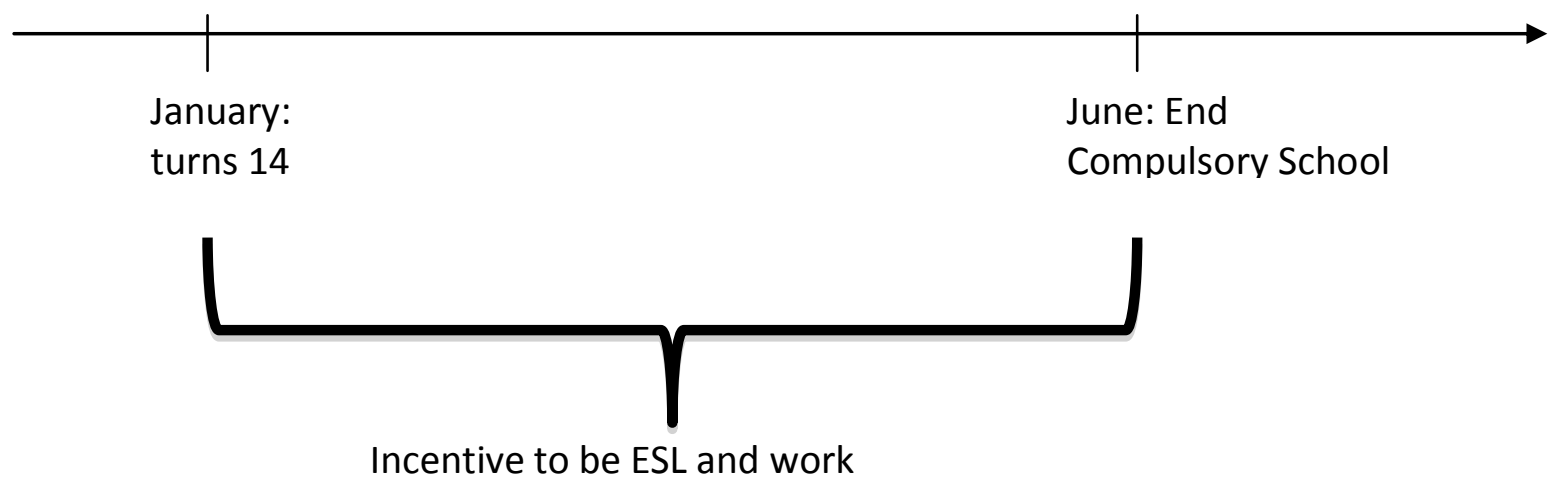

Individual born in November 1963: Pre-reform (is 17 in 1980).

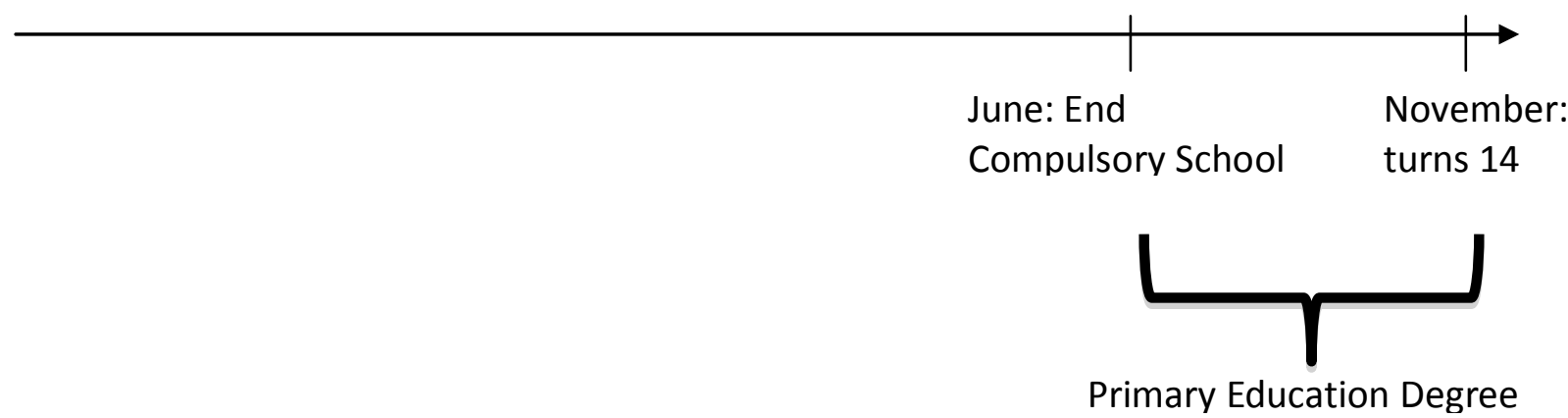


Figure A2. Incentives of individuals born at the beginning and end of the year after the reform.

Individual born in January 1970: Post-reform (aged 10 in 1980)

Calendar year 1984 (turns 14)

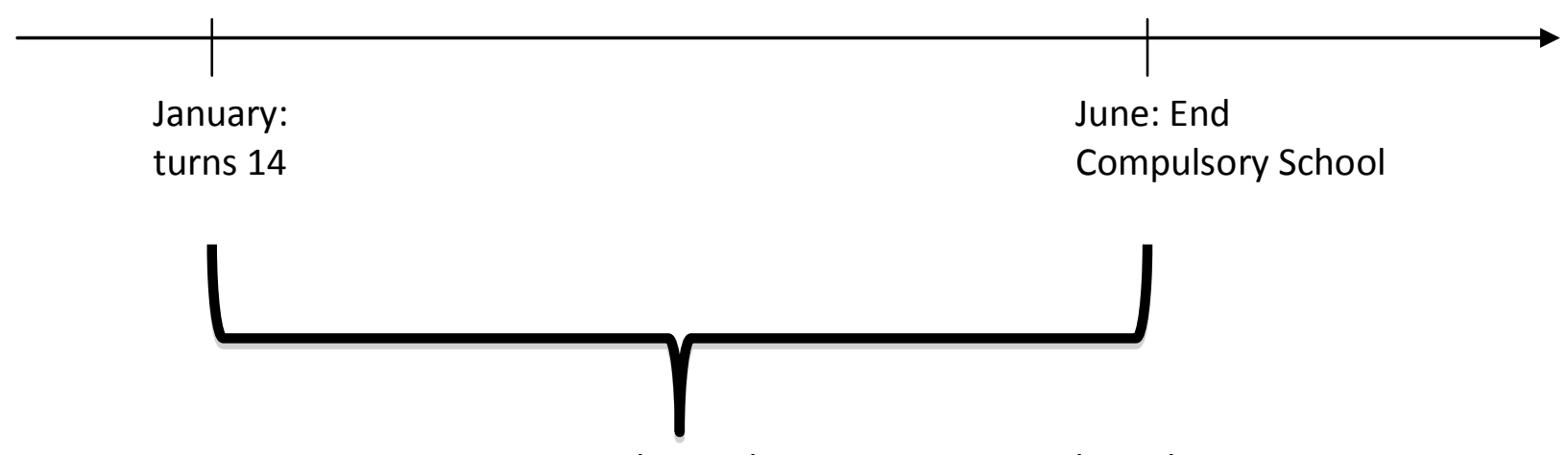

NO Incentive to be ESL because cannot work until 16

Individual born in November 1970: Post-reform (aged 10 in 1980).

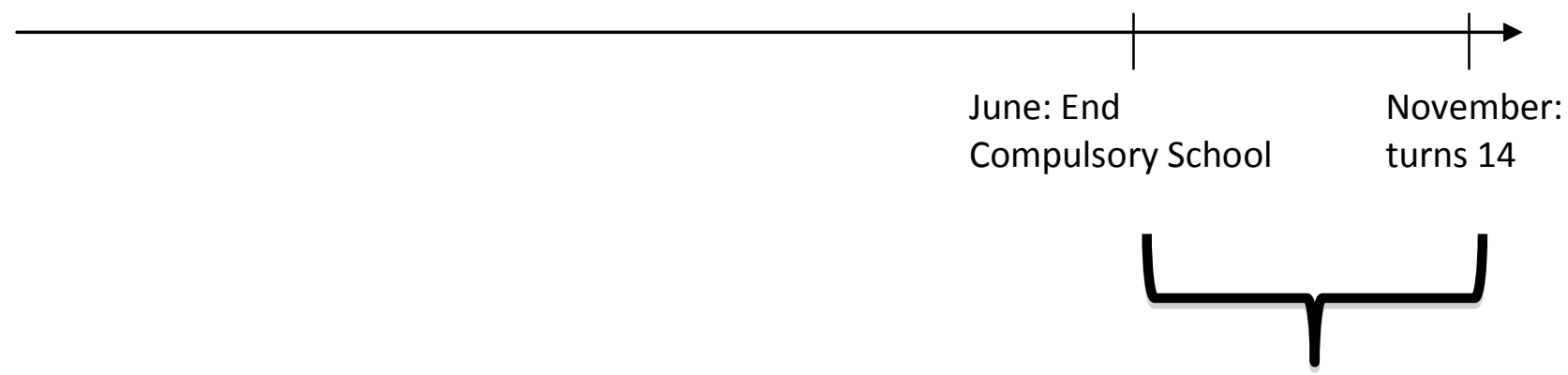

NO Incentive to be ESL because cannot work until 16 
Figure A3. Summary of labor market and education reforms and differential incentives of individuals born at the beginning and end of the year.

$\begin{array}{cc}\text { 1980: LM } & 1990: \\ \text { reform } & \text { Education } \\ \text { reform }\end{array}$

Age Legal Work

Age Compuls. Educ.

Born first

months year

months year
14

14
16

14

compulsory

education

Incentive

complete

compulsory

education
16

16
Incentive stay in

education until

16

Incentive leave school at 16;

before

compulsory

education

Incentive

complete

Incentive stay in

education until 16 compulsory

education 
Table A1. ESL and dropout using 2001 census data.

\begin{tabular}{lcc}
\hline & ESL & DROPOUT \\
\hline Treat & $0.822^{* *}$ & $0.902^{* *}$ \\
& $(0.340)$ & $(0.391)$ \\
Treat*Post & {$[0.05]$} & {$[0.07]$} \\
& $-0.963^{* *}$ & $-1.804 * * *$ \\
& $(0.374)$ & $(0.495)$ \\
Cohort FE & {$[0.02]$} & {$[0.00]$} \\
Observations & $X$ & $X$ \\
R-squared & 239,154 & 239,154 \\
\hline
\end{tabular}

Robust standard errors in parentheses

$* * * \mathrm{p}<0.01, * * \mathrm{p}<0.05, * \mathrm{p}<0.1$

Note: The dependent variable is the probability of being an ESL or a dropout multiplied by 100. Regressions include cohort fixed effects. "Treat" are individuals born in months 3, 4 and 5 and the control group are those born in months 8, 9 and 10. Includes cohorts from 1960 to 1975 (cohort of 1966 excluded). Robust standard errors clustered at the cohort level in parentheses and p-values of the wild bootstrap procedure in brackets. Source: 2001 Census (5\% sample). 
Table A2. Regression discontinuity results for the educational outcomes using 2001 census data.

\begin{tabular}{|c|c|c|c|c|c|c|c|c|}
\hline & \multicolumn{4}{|c|}{ All Cohorts Included } & \multicolumn{4}{|c|}{ Excluding the 1966 Cohort } \\
\hline & ESL & DROPOUT & ESL & DROPOUT & ESL & DROPOUT & ESL & DROPOUT \\
\hline \multirow[t]{3}{*}{ Post } & $0.907 * * *$ & $1.613^{* * *}$ & $0.917^{* *}$ & $1.640^{* * *}$ & 0.110 & -0.476 & 0.679 & 0.046 \\
\hline & $(0.259)$ & $(0.333)$ & $(0.315)$ & $(0.326)$ & $(0.485)$ & $(0.601)$ & $(0.517)$ & $(0.706)$ \\
\hline & {$[0.01]$} & {$[0.00]$} & {$[0.00]$} & {$[0.00]$} & [0.82] & [0.46] & [0.16] & [0.98] \\
\hline \multirow[t]{3}{*}{ Treat*Post } & -0.485 & $-0.928 * *$ & $-1.009 * *$ & $-1.715^{* * *}$ & $-0.770 *$ & $-1.211 *$ & $-1.209 * *$ & $-1.640 * *$ \\
\hline & $(0.313)$ & $(0.380)$ & $(0.402)$ & $(0.396)$ & $(0.421)$ & $(0.574)$ & $(0.447)$ & $(0.601)$ \\
\hline & {$[0.13]$} & {$[0.02]$} & {$[0.01]$} & {$[0.00]$} & {$[0.09]$} & {$[0.06]$} & {$[0.01]$} & {$[0.04]$} \\
\hline \multirow[t]{3}{*}{ Trend } & $-0.128 * * *$ & $-0.103 * * *$ & 0.020 & 0.115 & $-0.090 * * *$ & $-0.064 *$ & 0.094 & 0.140 \\
\hline & (0.014) & (0.016) & $(0.062)$ & $(0.073)$ & (0.030) & $(0.031)$ & $(0.057)$ & $(0.086)$ \\
\hline & {$[0.00]$} & {$[0.00]$} & {$[0.71]$} & {$[0.16]$} & [0.03] & [0.09] & [0.11] & [0.16] \\
\hline \multirow[t]{3}{*}{ Post*Trend } & $0.059^{*}$ & -0.046 & $-0.235^{* *}$ & $-0.484 * * *$ & -0.014 & $-0.110 *$ & $-0.345 * * *$ & $-0.459 * * *$ \\
\hline & $(0.028)$ & $(0.032)$ & $(0.094)$ & $(0.120)$ & $(0.060)$ & $(0.060)$ & $(0.088)$ & $(0.154)$ \\
\hline & {$[0.16]$} & {$[0.25]$} & {$[0.00]$} & {$[0.00]$} & {$[0.82]$} & [0.10] & {$[0.00]$} & {$[0.01]$} \\
\hline \multirow[t]{3}{*}{ Treat } & -0.069 & $-1.064 * * *$ & 0.207 & $-0.648 * *$ & $0.891^{*}$ & 0.516 & $1.198^{*}$ & 0.755 \\
\hline & (0.359) & (0.309) & $(0.394)$ & $(0.300)$ & $(0.497)$ & $(0.645)$ & $(0.561)$ & $(0.648)$ \\
\hline & {$[0.85]$} & {$[0.01]$} & {$[0.59]$} & {$[0.03]$} & {$[0.11]$} & [0.43] & {$[0.03]$} & [0.24] \\
\hline \multirow[t]{3}{*}{ Trend^2 } & & & 0.001 & 0.002 & & & $0.002 *$ & $0.002^{*}$ \\
\hline & & & $(0.001)$ & $(0.001)$ & & & $(0.001)$ & $(0.001)$ \\
\hline & & & [0.43] & [0.23] & & & {$[0.10]$} & {$[0.11]$} \\
\hline \multirow[t]{3}{*}{ Post*Trend^2 } & & & 0.000 & 0.000 & & & -0.001 & -0.001 \\
\hline & & & $(0.001)$ & $(0.001)$ & & & $(0.001)$ & $(0.001)$ \\
\hline & & & {$[0.94]$} & {$[0.87]$} & & & [0.69] & [0.58] \\
\hline Cohort FE & $x$ & $\mathrm{x}$ & $x$ & $\mathrm{x}$ & $\mathrm{x}$ & $\mathrm{x}$ & $x$ & $\mathrm{x}$ \\
\hline Month Birth FE & $\mathrm{x}$ & $x$ & $\mathrm{x}$ & $\mathrm{x}$ & $\mathrm{x}$ & $\mathrm{x}$ & $x$ & $\mathrm{x}$ \\
\hline Observations & 160 & 160 & 160 & 160 & 150 & 150 & 150 & 150 \\
\hline R-squared & 0.972 & 0.972 & 0.974 & 0.973 & 0.972 & 0.972 & 0.974 & 0.974 \\
\hline
\end{tabular}

Robust standard errors in parentheses

$* * * \mathrm{p}<0.01, * * \mathrm{p}<0.05, * \mathrm{p}<0.1$

Note: The dependent variable is the probability of being an ESL or a dropout multiplied by 100. Data is collapsed at the level of month and year of birth and the regressions include cohort (year of birth) and month-of-birth fixed effects. "Treat" are individuals born in months 1 to 5 and the control group are those born in months 8 to 12. Post are those individuals that turn 14 after the reform: those born after month 6 (June) of the 1966 cohort. The sample includes all cohorts from 1960 to 1975 (the last four columns exclude the 1966 cohort). The regressions include either a linear pre-reform and a linear post-reform trend or both a linear and quadratic pre and post reform trend. Robust standard errors clustered at the cohort level in parentheses and p-values of the wild bootstrap procedure in brackets. Source: 2001 Census (5\% sample). 
Table A3. Means of the outcome variables for treated and control before and after the policy.

\begin{tabular}{|c|c|c|c|c|c|c|}
\hline & \multicolumn{6}{|c|}{ MEN } \\
\hline & \multicolumn{3}{|c|}{ Treated } & \multicolumn{3}{|c|}{ Control } \\
\hline & Before & After & Difference & Before & After & Difference \\
\hline ESL & 23.56 & 12.82 & -10.74 & 21.72 & 12.16 & -9.56 \\
\hline \multirow[t]{4}{*}{ DROPOUT } & 54.06 & 44.02 & -10.04 & 52.07 & 43.61 & -8.46 \\
\hline & \multicolumn{6}{|c|}{ WOMEN } \\
\hline & \multicolumn{3}{|c|}{ Treated } & \multicolumn{3}{|c|}{ Control } \\
\hline & Before & After & Difference & Before & After & Difference \\
\hline ESL & 23.65 & 9.60 & -14.05 & 22.33 & 9.80 & -12.53 \\
\hline DROPOUT & 52.87 & 35.89 & -16.98 & 51.67 & 36.18 & -15.49 \\
\hline
\end{tabular}

\section{Data Appendix: Spanish Labor Force Survey}

The Spanish Labor Force Survey or "Encuesta de Población Activa" (EPA) is a rotating quarterly survey carried out by the Spanish National Statistical Institute (Instituto Nacional de Estadística, INE). The planned sample size consists of about 64,000 households with approximately 150,000 adult individuals. Although the survey has been conducted since 1964, publicly released cross-sectional files are available only from 1977. The 1977 questionnaire was modified in 1987 (when a set of retrospective questions were introduced), in the first quarter of 1992, in 1999 and 2004. The EPA provides fairly detailed information on labor force status, education and family background variables but, like most of the other European-style labor force surveys, no information on health is provided. The reference period for most questions is the week before the interview. 